Review

\title{
Optically Active Selenoxides: Structural and Synthetic Aspects
}

Dorota Krasowska $^{1, *(\mathbb{D}, \text { Luca Sancineto }}{ }^{1,2, *}$, Małgorzata Deska ${ }^{3}$ and Józef Drabowicz ${ }^{1,3, *(\mathbb{D})}$

1 Centre of Molecular and Macromolecular Studies, Polish Academy of Sciences, Division of Organic Chemistry, Sienkiewicza 112, 90-363 Łódź, Poland

2 Department of Pharmaceutical Sciences, University of Perugia, Group of Catalysis and Organic Green Chemistry via del Liceo 1, 06123 Perugia, Italy

3 Jan Dlugosz University in Czestochowa, Institute of Chemistry, Armii Krajowej 13/15, 42-200 Czestochowa, Poland; m.deska@ajd.czest.pl

* Correspondence: dkrasowska@gmail.com (D.K.); luca.sancineto@unipg.it (L.S.); draj@cbmm.lodz.pl or j.drabowicz@ajd.czest.pl (J.D.); Tel.: +48-510-812-551 (J.D.)

Received: 30 January 2020; Accepted: 20 February 2020; Published: 1 March 2020

Abstract: Synthetic approaches to the preparation of non-racemic selenoxides and the problem of their optical stability are discussed in this mini review.

Keywords: selenoxides; chirality; stereogenic selenium atom; asymmetric synthesis; optical resolution; racemization

\section{Introduction}

Sulfoxides are the logical and obvious reference point when one is considering the reactivity and optical activity of selenoxides. This is due to the fact that the reactivity of both groups of heterorganic derivatives of general structures $\mathbf{1}$ and $\mathbf{2}$ (Figure 1) is dominated mainly by the presence of a highly polarized heteroatom-oxygen bond, and their optical activity is associated with their tetrahedral geometry, which induces the optical activity of compounds in which two different carbon chains and/or rings are bonded to a stereogenic heteroatom.<smiles>[R][Sb]([R])(=O)I</smiles>

1<smiles>[R][SH]([R])([13CH3])=O</smiles>

2

Figure 1. General structure of selenoxides and sulfoxides.

The highly polarized heteroatom-oxygen bond is responsible for the interesting oxidative properties of sulfoxides [1] and selenoxides [2], and their ability to:

a) generate the $\alpha$-carbanions 3 [3] or 4 [4] for compounds containing the acidic $\alpha$-methylene hydrogen atoms $1 \mathbf{a}$ or $2 \mathbf{a}$ (Scheme 1);

b) undergo an internal type elimination of the E2 type for compounds containing $\beta$-hydrogen atoms, which leads to the formation of the corresponding, generally very unstable, seleninic 5 or sulfenic 6 acids and unsaturated carbon derivatives 7 (Scheme 1) [5,6]. It should be noted here that both acids can exist as chiral tetravalent (5a or $\mathbf{6 a}$ ) or achiral divalent (5b [7-9] or $\mathbf{6 b}$ [10-12]) tautomers. 


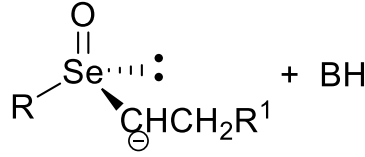

3<smiles>[13BH][13BH]</smiles><smiles>[R]CC[13C]([R])([13CH3])[O-]</smiles>

1a

temperature below $50^{\circ} \mathrm{C}$<smiles>[R][Se]([13CH3])([13CH3])O</smiles>

$5 b$

$$
\begin{aligned}
& \mathrm{CH}_{2}=\mathrm{CHR}^{1} \\
& \quad 7
\end{aligned}
$$<smiles></smiles>

4<smiles>[BH3-]C</smiles>

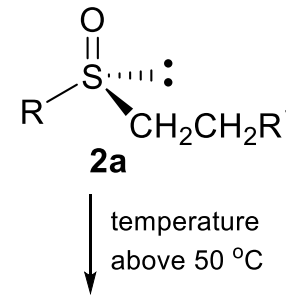

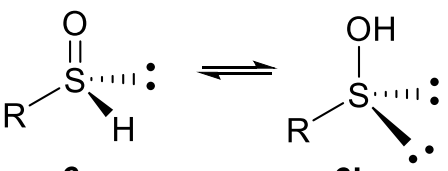

$6 a$ 6b

Scheme 1. Deprotonation and elimination reactions of selenoxides and sulfoxides.

When considering the optical activity of unsymmetrical selenoxides, it should be noted that their pyramidal configuration at selenium was for the first time proved only in 1946 by mixed crystal studies $[13,14]$ and that the first attempts to resolve 4-carboxydiphenyl selenoxide 8 and 4-carboxyphenyl methyl selenoxide 9 (Figure 2) via diastereoisomeric salts with enantiomerically pure amines were unsuccessful [15].<smiles>[R][Sb](C)(=O)c1ccc(C(=O)O)cc1</smiles>

$$
\begin{aligned}
& \text { 8; } R=P h \\
& \text { 9; } R=M e
\end{aligned}
$$

Figure 2. 4-Carboxydiphenyl selenoxide 8 and 4-carboxyphenyl methyl selenoxide 9.

The failure to observe resolution, which was in sharp contrast with the ease of resolution of the related sulfoxides [16] (due to the addition of water to unsymmetrical selenoxides, which should give rise to symmetrical dihydroxides) was mentioned in this paper. However, it was rejected by the authors because specific rotation of a dry sample of diastereoisomeric salts of the selenoxide 8 with enantiomerically pure $\alpha$-phenylethylamine was observed by recrystallizing it from dry ethyl acetate was not changed. An open suggestion that the inability to isolate selenoxide enantiomers is due to the rapid formation of hydrates in the presence of water was formulated only in 1952 in a review paper [17]. This reaction is illustrated for the selenoxide 1a and the formed dihydroxyselenuranes $\mathbf{1 0}$ in Scheme 2. 
<smiles>[R]C[C@H](CO)S([R])(=O)=O</smiles>

(S)-1a<smiles>[R]CC[Ge]([R])(O)O</smiles>

10<smiles>[R]CC[Se]([R])(=O)CO[C@H]1CO1</smiles>

$(R)-1 \mathrm{a}$

\section{descriptors $(S)$ and $(R)$ are valid, \\ if in selenoxide $1 \mathrm{a}$, according to the Cahn-Ingold-Prelog rules, $\mathrm{R}$ has priority over $\mathrm{CH}_{2} \mathrm{CH}_{2} \mathrm{R}^{1}$}

Scheme 2. Rapid hydrate formation by selenoxides in the presence of water.

This proposal was later supported by NMR experiments using benzyl phenyl selenoxide $\mathbf{1 1}$ as the model compound according to which the chemical shift between the nonequivalent methylene protons $\mathrm{H}_{\mathrm{A}}$ and $\mathrm{H}_{\mathrm{B}}$ disappeared in an aqueous solution, which indicates the apparent loss of stereogenity of the selenium atom in this medium due to the formation of the corresponding dihydroxyselenurane [18]. The configurational instability in aqueous media was also observed for selenoxides 12 [19] and 13 (Figure 3) [20]. It is interesting to note that racemic and meso forms of selenoxide $\mathbf{1 3}$ were separated.

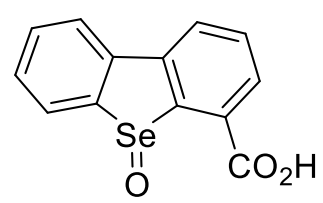

12<smiles>c1ccc(Cc2ccccc2)cc1</smiles>

13

Figure 3. Selenoxides $\mathbf{1 2}$ and $\mathbf{1 3}$ configurationaly instable in aqueous media.

According to a current terminology, dihydroxyselenuranes such as $\mathbf{1 0}$ can be considered as hypervalent molecules [21-23] Due to the presence of two apical hydroxyl groups in the trigonal bipyramid formed as an intermediate, they are achiral [24]. It can be expected, that the isolation of selenoxides in enantiomerically pure, or at least enriched form, could be possible when the formation of hydrated form is slowed down. This can be realized most easily by introduction at least a single, sterically demanding substituent. Successful experiments on the isolation of optically active selenoxides, described after 1970, fully confirmed this assumption. It is the intent of this mini review to present the available information on the preparation and optical stability of selenoxides, in order to stimulate the additional research on this topic. It should be noted here that in the years 1987-1995 short reviews were published in Japanese by Japanese authors conducting research on this topic. [25-27]. There are also two brief accounts in English that describe experiments on the synthesis, stereochemical aspects and the application in asymmetric synthesis of chiral chalcogen oxides carried out in the laboratories of authors, in which optically active selenoxides are also mentioned [28,29]. A few year later, a brief discussion devoted to optically active selenoxides was included into the Chapter 16 of "The Chemistry of Organic Selenium and Tellurium Compounds" from Patai's "Chemistry of Functional Groups" [30].

Below, we are going to discuss the synthesis of optically active selenoxides, which have been obtained in the form of diastereomeric mixtures or in enantiomeric form since 1970 using the following procedures:

a) reaction of diastereoisomerically pure precursors;

b) asymmetric oxidation of prochiral selenides;

c) chromatographic and nonclassical resolution of racemates by forming complexes with an optically active hydrogen bond donor; 
d) kinetic resolution of racemates;

e) reaction of enantiopure, cyclic seleninic esters with organometallic reagents.

\section{Synthesis of Optically Active Selenoxides}

\subsection{Diastereoisomeric Selenoxides}

The first selenoxides whose optical activity results from the presence of a stereogenic selenium atom constitute diastereoisomeric, steroidal selenoxides 14 and 15, which were described in 1970 [31]. Their synthesis was based on the oxidation of $6 \beta$-phenylseleno- $5 \alpha$-cholestane 17 which contains a prochiral divalent selenium atom (prepared by the reaction of $6 \alpha$-methanesulphonyloxy- $5 \alpha$-cholestane 16 with sodium benzeneselenolate) with ozone [32]. It was found that this asymmetric oxidation, carried out in dichloromethane at $-78{ }^{\circ} \mathrm{C}$, gave a mixture of the selenoxides $(R)-6 \beta-14$ and $(S)-6 \beta-15$ in the ratio $2: 1$. Separated $\mathrm{p}$ by chromatography at $-50{ }^{\circ} \mathrm{C}$ did not interconvert at temperatures between $-78{ }^{\circ} \mathrm{C}$ and $25^{\circ} \mathrm{C}$ in organic solvent in the presence of water. This indicates that their racemization via reversible hydrate formation (or pyramidal inversion) is not observed under these conditions. However, both diastereoisomerically pure selenoxides $\mathbf{1 4}$ and $\mathbf{1 5}$ were found to decompose at room temperature, affording only 5- $\alpha$-cholest-6-ene $\mathbf{1 8}$ and benzeneseleninic acid $\mathbf{1 9}$ (Scheme 3). It is interesting to note that the (S)-6 $6 \beta-15$ gave the olefin $\mathbf{1 8}$ after $4 \mathrm{~h}$ at $0{ }^{\circ} \mathrm{C}$, while the other one remains unchanged. These difference $\mathrm{i}$ in the decomposition rate was proposed to be related with the cyclic intramolecular mechanism common to syn-eliminations [33]. In line with this mechanism, the transition state 20a which leads from the (S)-6- $\beta$-phenylselenoxide $\mathbf{1 5}$ to 5 a-cholest-6-ene $\mathbf{1 8}$ is appreciably less sterically compressed than that of the transition state $\mathbf{2 0 b}$ responsible for the formation of the unsaturated steroid 18 from the (R)-isomer 14 (Scheme 3).

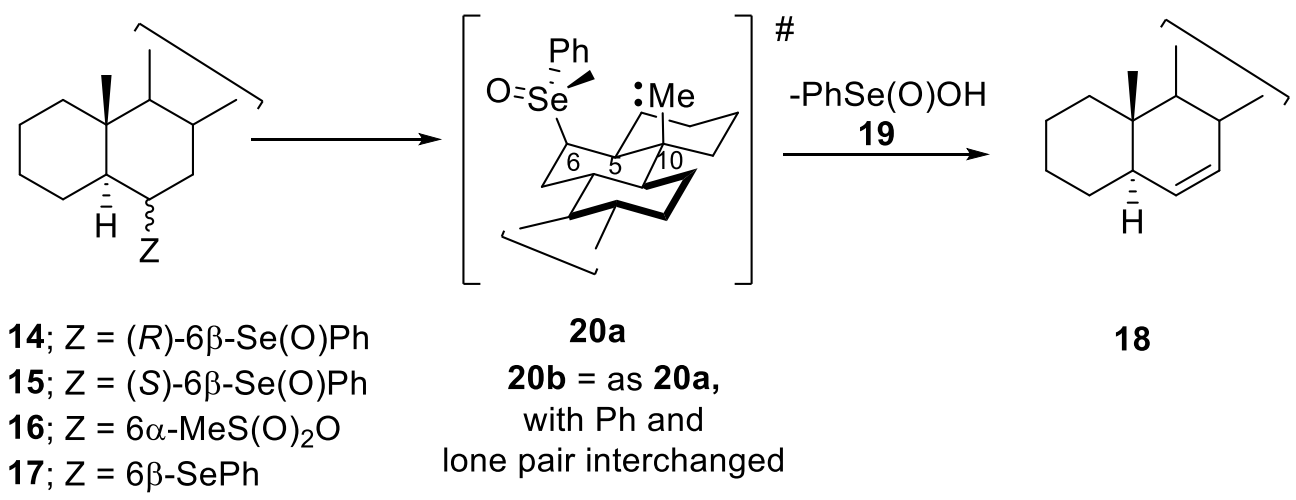

Scheme 3. Formation of unsaturated steroid 18 from selenoxide 14.

Generation of diastereoisomeric steroidal selenoxides 21 and 22, which were too labile to be isolated was observed during the oxidation of $7 \beta$-phenylselenocholesteryl benzoate 23 , (prepared by the reaction of $7 \alpha$-bromocholesteryl benzoate 24 with sodium benzeneselenolate), with ozone at $-70{ }^{\circ} \mathrm{C}$ in a methylene chloride solution. Their configurational stability and the absolute configuration at the newly generated stereogenic center on a selenium atom was suggested, taking into account an observation that the 3-benzoate of coprost-6-en-3b,5-diol 26 and 7-dehydrocholesteryl benzoate 25 were formed in approximately equal yields of $45 \%$. Interestingly, when temperature was slowly raised, the presence of 26 was detected by thin layer chromatography (TLC) at about $-25^{\circ} \mathrm{C}$ whilst 25 appeared only at about -5 to $0{ }^{\circ} \mathrm{C}$ (Scheme 4). If the selenoxides 21 and 22 were configurationally unstable it the interconversion of $\mathbf{2 2}$ to $\mathbf{2 1}$ should lead predominantly to the product $\mathbf{2 6}$, which was not detected [34]. The sequential treatment of 4-aza-5-pregnene-3,20-dione 27 with benzeneselenenyl chloride 28 and 1 equivalent of m-chloroperbenzoic acid (MCPBA) was found to afford a 2:1 mixture of selenoxide diastereomers (R)-30 and (S)-31 (Scheme 5). This mixture of selenoxide stereoisomers 
remained unchanged after one week. Whereas, the pure, major diastereoisomer $(R)-\mathbf{3 0}$ similarly treated epimerized to the same 2:1 mixture within $3 \mathrm{~h}$.

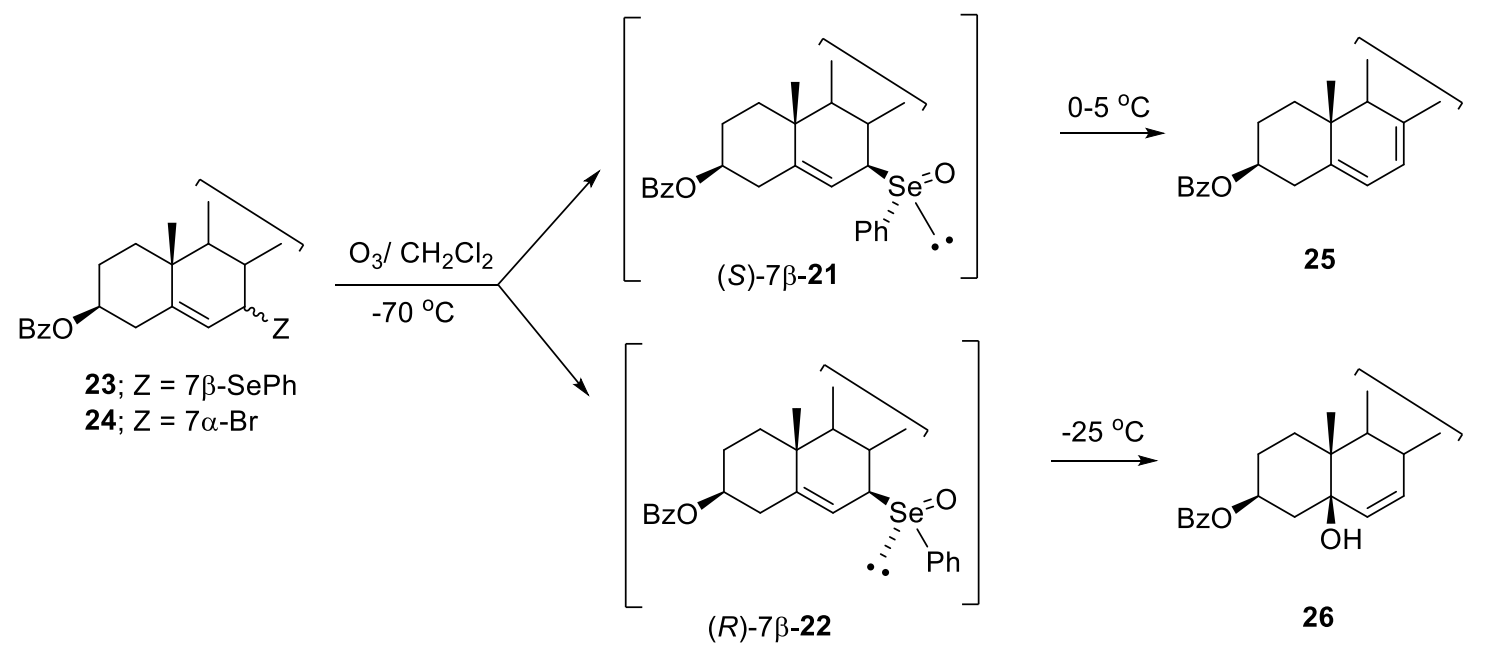

Scheme 4. Formation of 3-benzoate of coprost-6-en-3b,5-diol 26 and 7-dehydrocholesteryl benzoate 25.<smiles>CC1CC=C2NC(=O)CCC2(C)C1C</smiles>

27

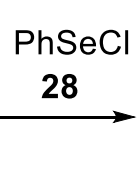<smiles>CC1CCC2(C)CCC(=O)NC1=C2[SbH]</smiles>

29

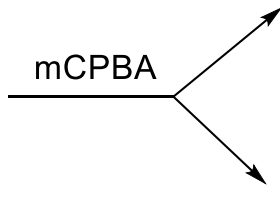

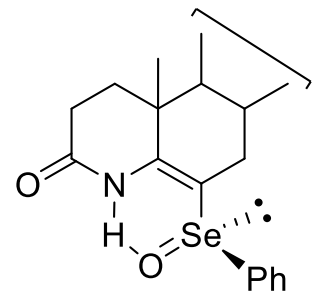

$(R)-30$

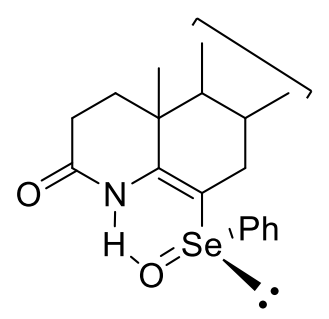

(S)-31

Scheme 5. Diastereoselective oxidation of azasteroidal selenide 29.

It was suggested that the 2:1 ratio reflects the relative thermodynamic stabilities of the two diastereoisomers [35]. The abnormally low field of the NMR signals of the enamidic hydrogen atoms in the stereoisomers $\mathbf{3 0}$ and $\mathbf{3 1}$ was related to the presence of strong intramolecular hydrogen bonds between the selenoxide oxygens and these hydrogen atoms. A series of diasteroisomeric hydroxyselenoxides $40-43$ containing the bornyl moiety was prepared by hydrolysis at $0{ }^{\circ} \mathrm{C}$ of diasteroisomeric chloroselenuranes $36-39(\mathrm{X}=\mathrm{Cl})$ which were formed rapidly $\left(10\right.$ min at $\left.0{ }^{\circ} \mathrm{C}\right)$ as single stereoisomers (89-100\% yield) upon the reaction of bicyclic hydroxyselenides 32-35 with $t$-butyl hypochlorite (Scheme 6). It was found that the treatment of selenoxide 40a with a base afforded an equilibrium mixture of 40a and 40b (2:1) whereas the treatment with an acid (HCIO4) of selenoxide $40 \mathrm{a}$ or a mixture of the selenoxides $40 \mathrm{a}$ and $40 \mathrm{~b}$ predominantly gave $40 \mathrm{a}$, and that selenurane 36 was formed both from $40 \mathrm{a}$ and a mixture of $40 \mathrm{a}$ and $40 \mathrm{~b}$. The starting chloroselenurane 36 was recovered as a single diastereomer (100\% yield) upon treatment of the selenoxide 40 with $\mathrm{HCl}$, A similar reaction of 40 with $\mathrm{HBr}$ gave bromoselenurane $\mathbf{4 4}$ (96\% yield). The reaction of the hydroxyselenoxide $\mathbf{4 0}$ with 
strong organic acids (3,5-dinitrobenzoic, $p$-toluenesulfonic or trifluoromethanesulfonic)in the presence of $\mathrm{MgSO}_{4}$ gave the corresponding selenuranes 44-47, respectively (Scheme 6) [36,37].

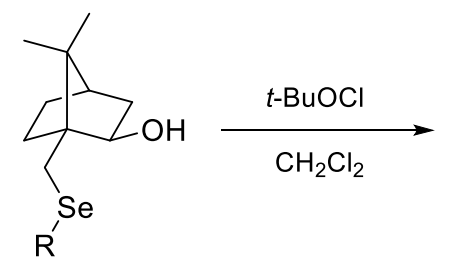
32, $\mathrm{R}=\mathrm{Ph}$
33, $\mathrm{R}=p-\mathrm{MeOC}_{6} \mathrm{H}_{4}$
34, $\mathrm{R}=p-\mathrm{CF}_{3} \mathrm{C}_{6} \mathrm{H}_{4}$
35, $\mathrm{R}=\mathrm{Me}$

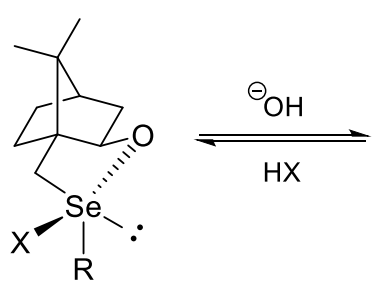

36, $\mathrm{R}=\mathrm{Ph} ; \mathrm{X}=\mathrm{Cl}$

37, $\mathrm{R}=p-\mathrm{MeOC}_{6} \mathrm{H}_{4} ; \mathrm{X}=\mathrm{Cl}$

38, $\mathrm{R}=p-\mathrm{CF}_{3} \mathrm{C}_{6} \mathrm{H}_{4} ; \mathrm{X}=\mathrm{Cl}$

39, $\mathrm{R}=\mathrm{Me} ; \mathrm{X}=\mathrm{Cl}$

44, $\mathrm{R}=\mathrm{Ph} ; \mathrm{X}=\mathrm{Br}$

45, $\mathrm{R}=\mathrm{Ph} ; \mathrm{X}=3,5-\mathrm{O}_{2} \mathrm{NC}_{6} \mathrm{H}_{2} \mathrm{CO}_{2}$

46, $\mathrm{R}=\mathrm{Ph} ; \mathrm{X}=p$ - $\mathrm{TolSO}_{3}$

47, $\mathrm{R}=\mathrm{Ph} ; \mathrm{X}=\mathrm{CF}_{3} \mathrm{SO}_{3}$

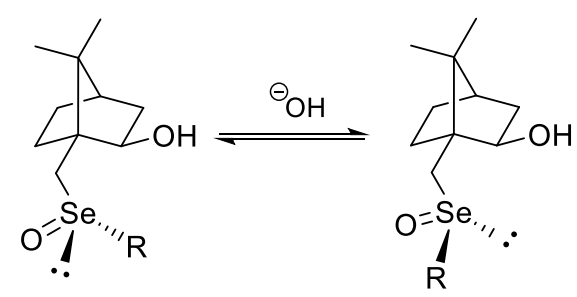

40a, $\mathrm{R}=\mathrm{Ph}$

41, $\mathrm{R}=p-\mathrm{MeOC}_{6} \mathrm{H}_{4}$

40b, $R=P h$

43, $\mathrm{R}=\mathrm{Me}$

Scheme 6. Hydrolysis of diasteroisomeric selenuranes 36-47.

It is well known that allyl selenoxides undergo very fast [2,3]sigmatropic rearrangement, producing allylic alcohols (Scheme 7), while vinyl selenoxides are able to eliminate selenic acid, which leads to the cumulene system (Scheme 8). The asymmetric version of both methods can be used to synthesize optically active alcohols or allenes, respectively [38-41].

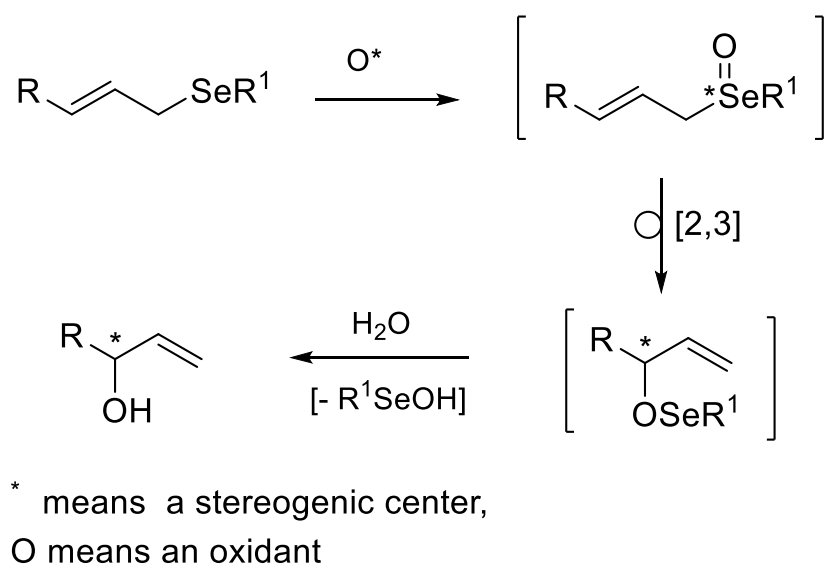

Scheme 7. [2,3]Sigmatropic rearrangement of allyl selenoxides generated in situ.

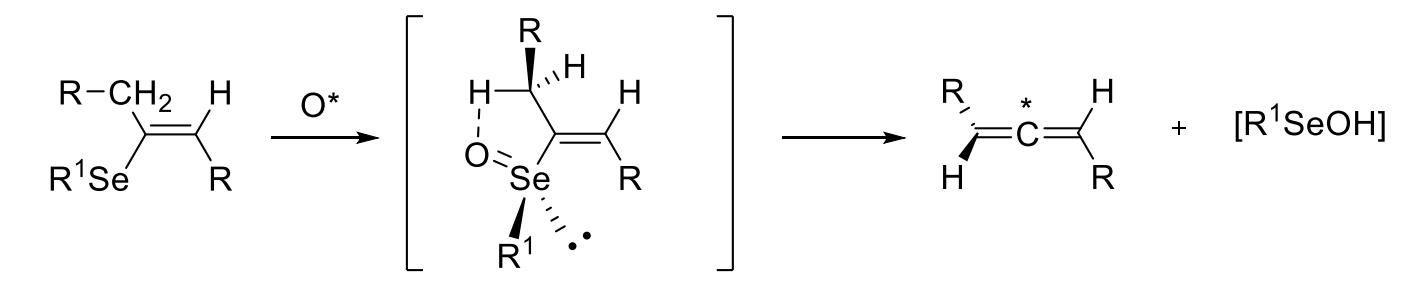

means a stereogenic center,

$O$ means an oxidant

Scheme 8. Oxidative conversion of vinyl selenides into allenes. 
The first example of this methodology, which was used in the preparation of optically active allylic alcohol, was reported in 1991 [42] and was based on the in situ generation of the optically active, diastereoisomerically enriched, geranyl [2.2]paracyclophanyl selenideoxide 49 by treatment of the corresponding optically active geranyl selenide 48 with meta-chloroperbenzoic acid (MCPBA). This protocol gave linalool 51 with $67 \%$ enantiomeric excess (ee) via selenenic ester $\mathbf{5 0}$ which was formed as a result of the [2,3]sigmatropic rearrangement of selenoxide 49 (Scheme 9).

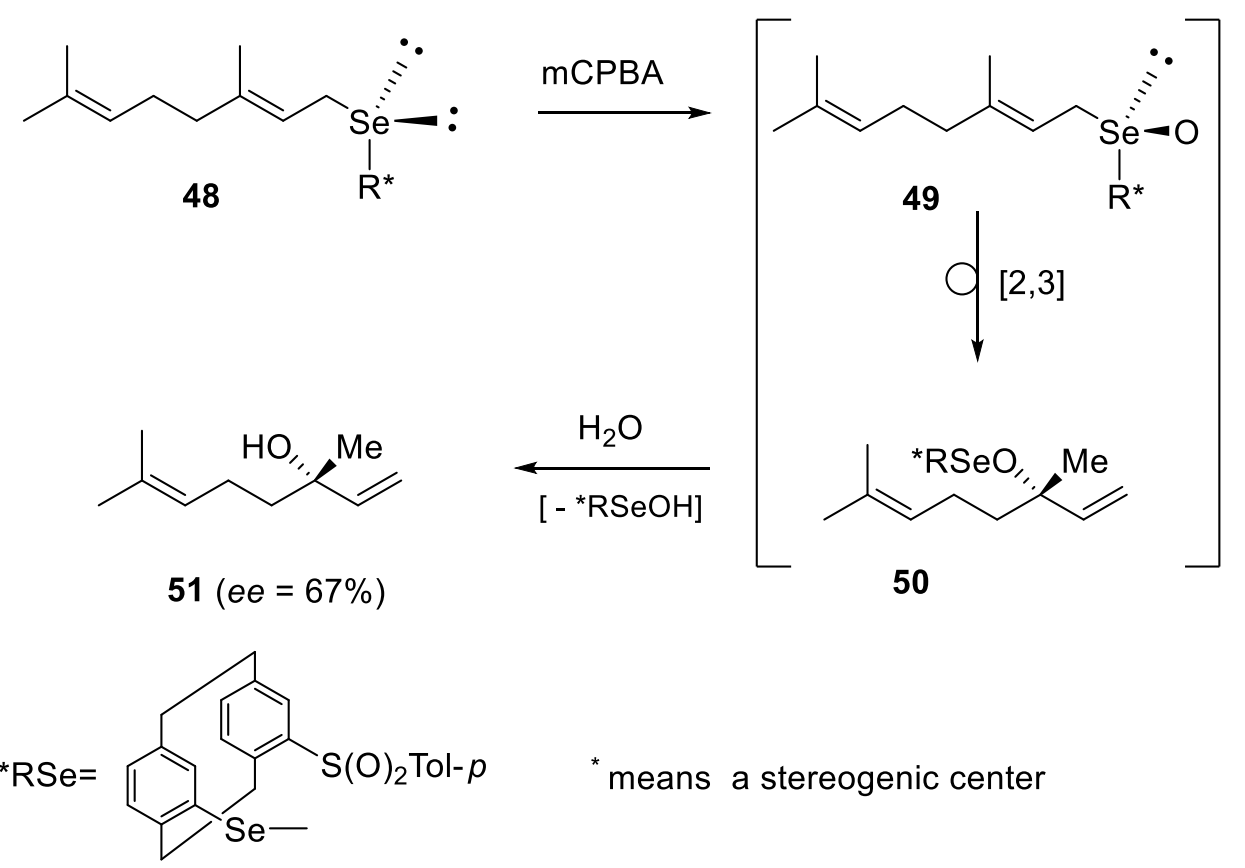

Scheme 9. Oxidative conversion of geranyl [2.2]paracyclophanyl selenide 49 into optically active linalool 51.

A similar oxidation of geranyl selenide 52 bearing a chiral ferrocenyl group afforded the corresponding diasteromeric selenoxides 53 , which upon the [2,3]sigmatropic rearrangement gave optically active linalool 51 in moderate yields and an improved ee (83\%) (Scheme 10) [43]. 

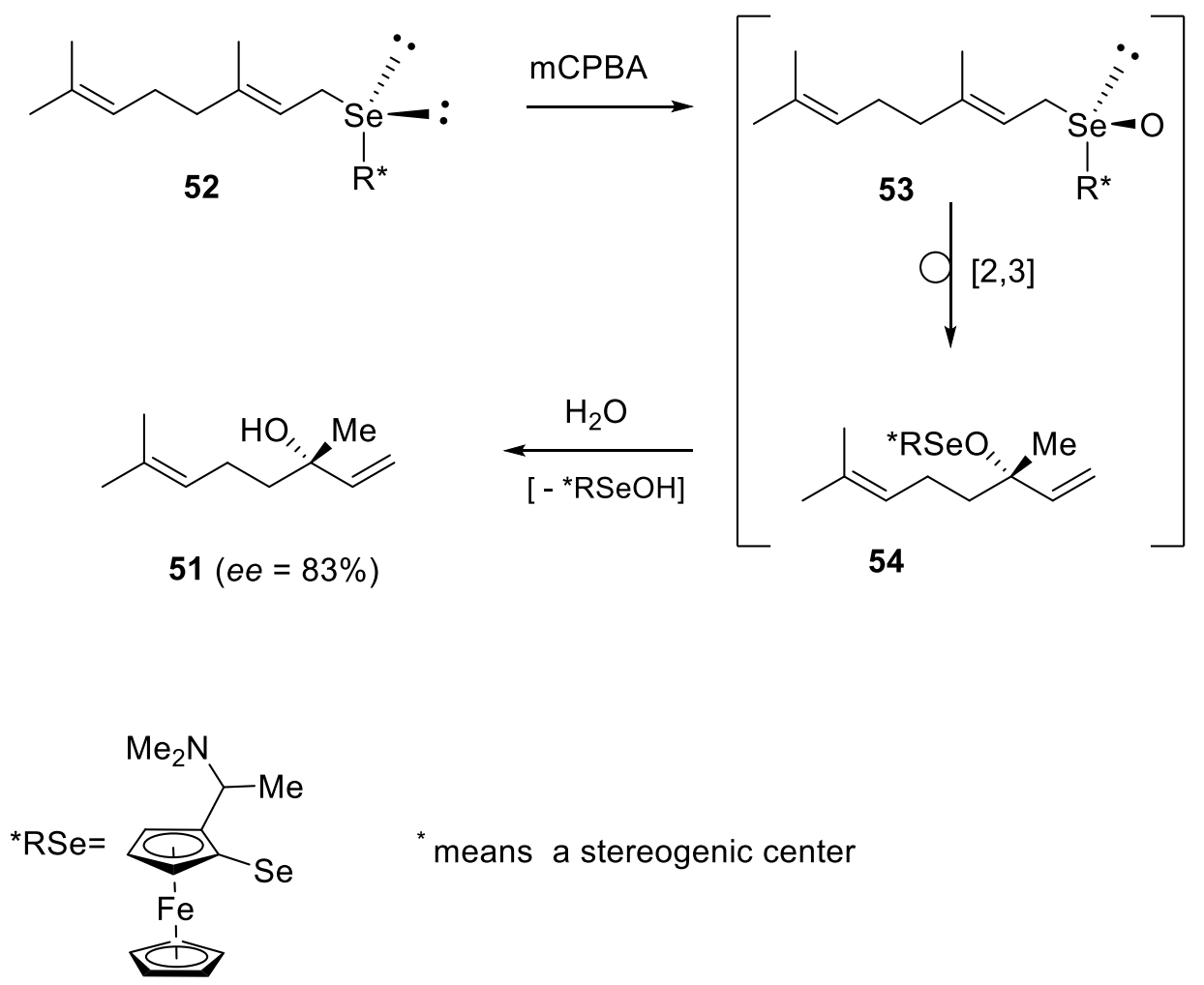

Scheme 10. Oxidative conversion of ferrocenyl selenide 52 into optically active linalool 51.

This approach was also applied in the synthesis of a series of cinnamyl selenides 55-57 bearing other chiral groups. The diasteroisomeric selenoxides $\mathbf{5 8 - 6 0}$ upon $[2,3]$ sigmatropic rearrangement gave, via diastereoisomeric esters 61-63, enantiomerically enriched 1-phenyl-2-propen-1-ol 64 in with ee in the range of 63-89\% (Scheme 11) [44]. The chiral, diasteroisomeric selenoxides 68-70 generated similarly from the corresponding optically active ferrocenyl vinylic selenides having (Z)-configuration 65-67 underwent the in situ seleninic acid elimination to afford axially chiral allenecarboxylic esters 71-73 in moderate chemical yields (21-59\%) with ee from 16 up to 89\% (Scheme 12) [43]. 


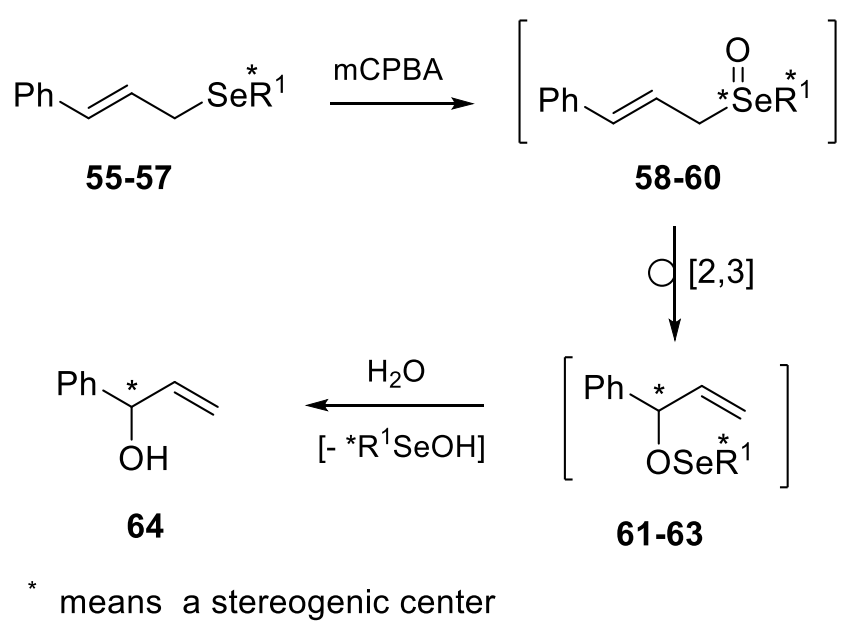

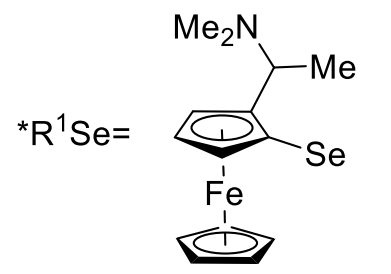

$55,58,61$<smiles>COCC1CCCN1c1ccccc1[Se]</smiles>

$56,59,62$<smiles>CC1(C)C2CCC1(C[Se])C(O)C2</smiles>

$57,60,63$

Scheme 11. Oxidative conversion of cinnamyl selenides 55-57 into optically active 1-phenyl-2-propen-1-ol 64.
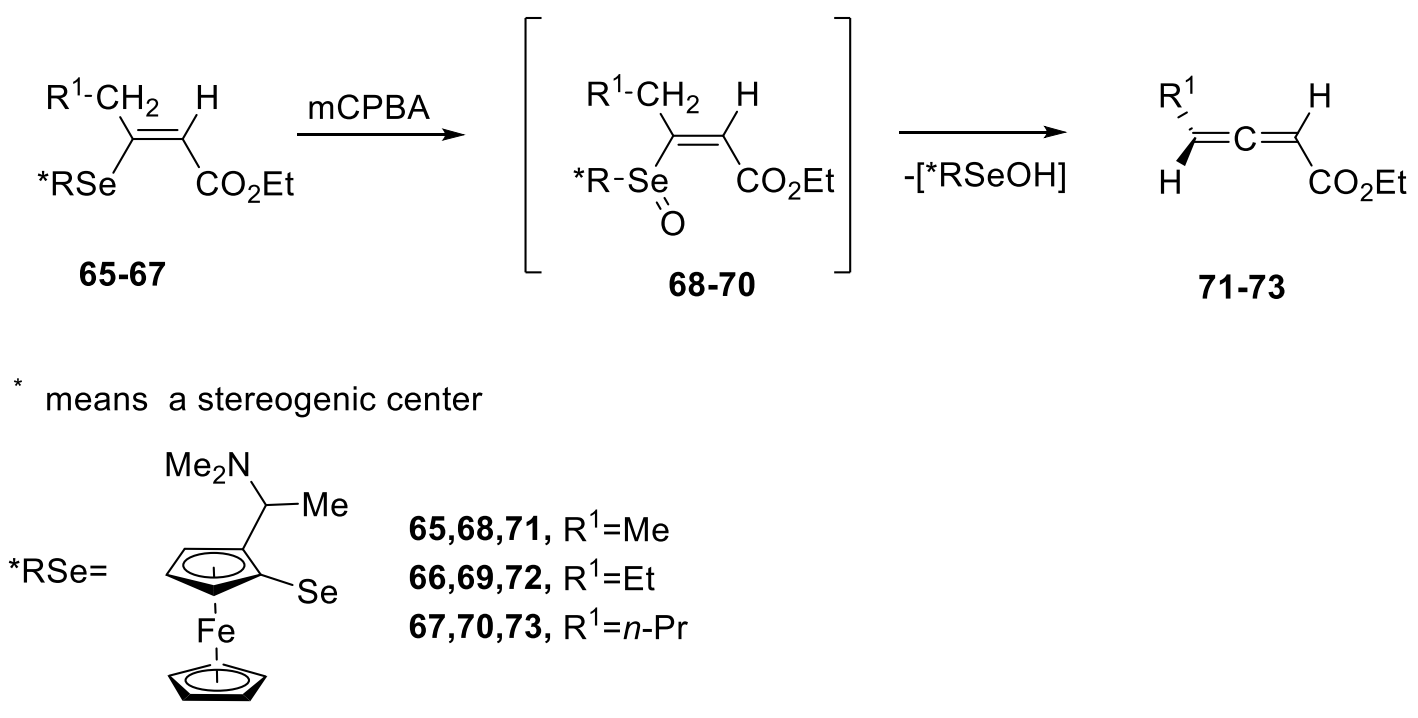

Scheme 12. Oxidative conversion of vinyl selenides 65-67 into allenes 71-73.

Two optically stable, diastereoisomeric selenoxides $\mathbf{7 6} \mathbf{a}-\mathbf{b}-\mathbf{7 7} \mathbf{a}-\mathbf{b}$ were prepared by oxidation of the 4-[(-)-menthyloxycarbonyl] phenyl aryl selenides 74-75 with t-butyl hypochlorite-pyridine-methanol (Scheme 13). The selenoxide 76a after five recrystallizations from methanol, was diastereoisomericaly pure (HPLC analysis using an achiral column). Dextrorotatry diastereoisomer $\mathbf{7 6 b}$ was also obtained from the mother liquid with 75\% diastereoisomeric excess. A similar oxidation of the selenide $\mathbf{7 5}$ gave, with slight asymmetric induction $(\mathrm{de}=7.6 \%)$, diastereoisomeric 4 -[(-)-menthyloxycarbonyl] phenyl 2,4,6-tri-t-butyphenyl selenoxides $\mathbf{7 7 a}-\mathbf{b}$. Fractional crystallization of this diastereoisomeric mixture 
gave a sample of the levorotatory diastereoisomer $77 \mathbf{a}$ having de $=31.1 \%$ (estimated by measurement of the ${ }^{77}$ Se NMR spectrum) [45].

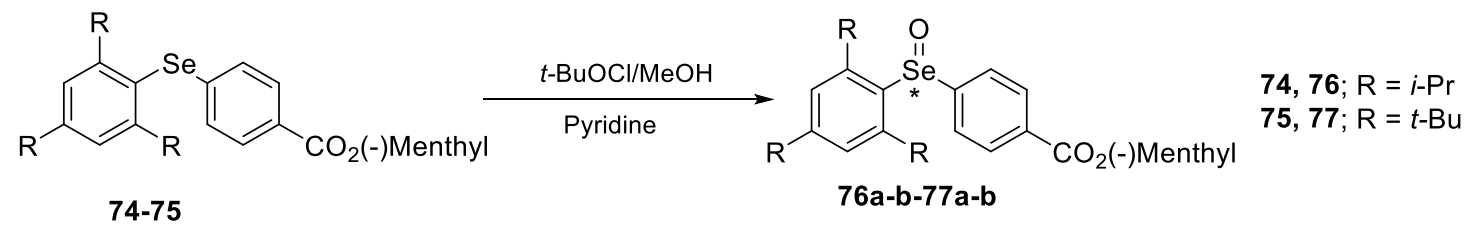

Scheme 13. Asymmetric synthesis of optically active diaryl selenoxides 76-77.

The levorotatory enantiomer of 4-[(-)-methoxycarbonyl] phenyl 2,4,6-tri-iso propyl phenyl selenoxide $\mathbf{7 8}$ was obtained by transesterification of diastereoisomerically pure 4-[(-)-menthyloxycarbonyl] phenyl 2,4,6-tri-isopropylphenyl selenoxide 76a in $N$, $\mathrm{N}$-dimethylformamide DMF) at room temperature (Scheme 14). On the other hand, transesterification of the levorotatory diastereoisomer $77 \mathbf{a}(\mathrm{de}=31.1 \%)$ with sodium methoxide in methanol gave a sample of the selenoxide $\mathbf{7 9}$ with $29 \%$ ee. s Its washing with hexane left a solid that showed only $13 \%$ ee, while a sample of the selenoxide $\mathbf{7 9}$ isolated from the hexane solution exhibited a much higher enantiomeric excess $(80 \%)$ [45]. The dehydration conversion of enantiomerically pure selenoxide (-)-78 ( $p$-toluenesulfonamide $\left(\mathrm{TsNH}_{2}\right) /$ dicyclohexylcarbodiimide (DCC)/ 4-(dimethylamino)pyridine (DMAP)//80 ${ }^{\circ} \mathrm{C}$ ) in 1,1,2-trichloroethane gave optically active 4-(methoxycarbonyl) phenyl(2,4,6-triisopropylphenyl)selenonium ( $\mathrm{N}$-toluene-4-sulfon)imide (-)- 80 in $29 \%$ chemical yield. Its enantiomeric excess was determined to be $80 \%$ by ${ }^{1} \mathrm{H}-\mathrm{NMR}$ measurement using an optically active shift reagent $\left\{\mathrm{Eu}(\mathrm{hfc})_{3}\right\}$ (Scheme 15) [46].<smiles>[R]c1cc([R])c([S+](=O)(=O)c2ccc(C(=O)OCCOC)cc2)c([R])c1</smiles>

$76 a$ or $77 a$<smiles>[R]c1cc([R])c([S+](=O)Oc2ccc(C(OC)OC)cc2)c([R])c1</smiles>

78-79

$$
\begin{aligned}
& \mathrm{R}=i-\operatorname{Pr},(-) 76 \mathrm{a}(d e=100 \%) \quad \square \quad(-)-78(e e=100 \%) \\
& \mathrm{R}=t-\mathrm{Bu},(-) 77 \mathrm{a}(\mathrm{de}=31 \%) \quad \Longrightarrow \quad(-)-79(e e=29 \%)
\end{aligned}
$$

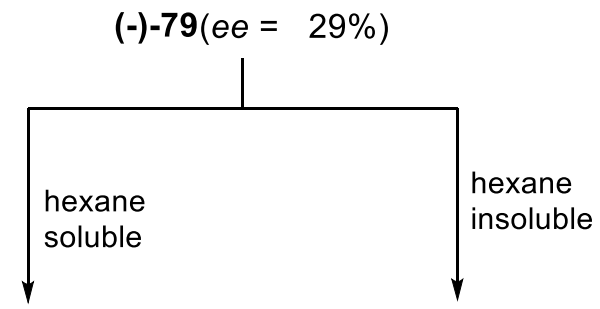

$$
(-)-79(e e=80 \%) \quad(-)-79(e e=13 \%)
$$

Scheme 14. Transesterification of diastereoisomerically pure selenoxide 76a with methanol. 
<smiles>[R]c1cc([R])c([Se](=O)c2ccc(C(C)=O)cc2)c([R])c1</smiles>

$(-)-78(e e=100 \%)$

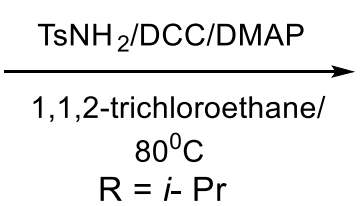

$(-)-80(e e=80 \%)$

Scheme 15. Conversion of enantiomerically pure selenoxide (-)-78 into optically active selenoniumimide $(-)-80$.

\subsection{Enantiomeric Selenoxides}

\subsubsection{Asymmetric Oxidation}

Among the different approaches to the synthesis of enantiomeric selenoxides, asymmetric oxidation of the prochiral, unsymmetrical selenides with optically active oxidizing agents can be considered the method of choice. The first asymmetric oxidations of methyl phenyl selenide 81 by chiral 2-sulfonyloxaziridines 89 a or 89 b, carried out in the Davis laboratory, was found to give the corresponding methyl phenyl selenoxide 85 with ee only around $9 \%$ ee under anhydrous conditions [47]. Later, $N$-(phenylsulfonyl) (3,3-dichlorocamphoryloxaziridine) $89 \mathrm{c}$ was found to be more efficient reagent for the enantioselective oxidation of prochiral selenides 81-84 Using this reagent, the corresponding alkyl aryl selenoxides $\mathbf{8 5 - 8 8}$ were isolated for the first time with ee hagher than $\mathbf{9 0 \% . . ( S c h e m e ~ 1 6 ) ~ [ 4 8 , 4 9 ] . ~}$

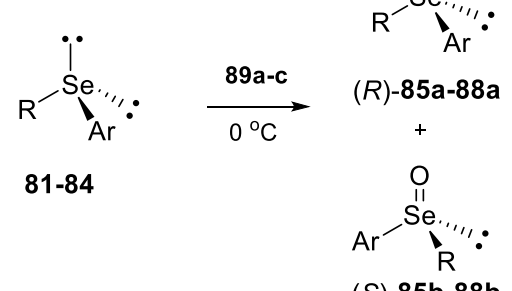

(S)-85b-88b

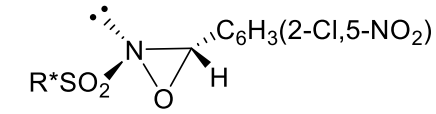

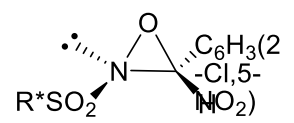

$(-)-(S, S)-89 \mathrm{a} \quad \mathrm{R}^{*}=\mathrm{D}-10$-camphor $\quad(+)-(R, R)-\mathbf{8 9} \mathrm{b}$

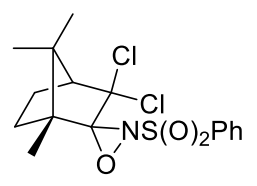

$(-)-89 c$

$(\mathbf{8 1}, \mathrm{R}=\mathrm{Me}, \mathrm{Ar}=\mathrm{Ph}) / \mathbf{8 9 a}$

$(81, \mathrm{R}=\mathrm{Me}, \mathrm{Ar}=\mathrm{Ph}) / \mathbf{8 9 c}$

$\left(82, \mathrm{R}=\mathrm{Me}, \mathrm{Ar}=2,4.6-\mathrm{i}-\mathrm{Pr}-\mathrm{C}_{6} \mathrm{H}_{2}\right) / 89 \mathrm{c}$

$\left(83, \mathrm{R}=\mathrm{Et}, \mathrm{Ar}=2,4.6-\mathrm{i}-\mathrm{Pr}-\mathrm{C}_{6} \mathrm{H}_{2}\right) / 89 \mathrm{c}$

$\left(84, \mathrm{R}=\mathrm{CH}_{2} \mathrm{C}_{6} \mathrm{H}_{4}-\mathrm{OMe}-\mathrm{p}, \mathrm{Ar}=2,4.6-\mathrm{i}-\mathrm{Pr}-\mathrm{C}_{6} \mathrm{H}_{2}\right) / 89 \mathrm{c}$

$85 a+85 b(e e=9-13 \%)$

$85 a+85 b(e e=95 \%)$

$86 a+86 b(e e=95 \%)$

$87 a+87 b(e e=91 \%)$

$88 a+88 b(e e=95 \%)$

Scheme 16. Asymmetric synthesis of optically active selenoxides 85-88.

The above-mentioned oxaziridines (+)-89a and (-)-89c were used also for the in situ generation of (E)- and (Z)-aryl cinnamyl selenoxides 92 and 93 by oxidation of the corresponding cinnamyl selenides $\mathbf{9 0}$ and $\mathbf{9 1}$. Their instant [2,3]sigmatropic rearrangement to allylic selenenates $\mathbf{9 4 - 9 5}$ afforded 1-phenylallyl alcohol 64 as the final product (Scheme 17) [49]. 


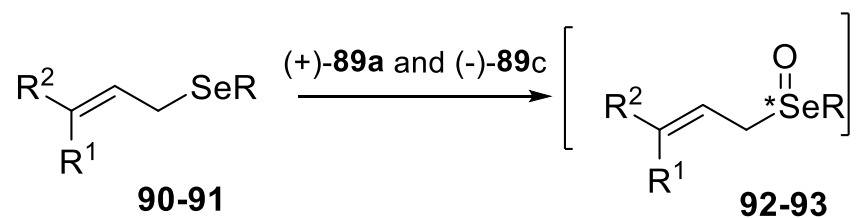

$$
\begin{aligned}
& \text { q[2,3] } \\
& \mathrm{R}_{\mathrm{OH}}^{\mathrm{R}^{2}} \stackrel{\mathrm{H}_{2} \mathrm{O}}{[-\mathrm{RSeOH}]} \\
& \left.\mathrm{R}_{\text {OSeR }}^{\mathrm{R}^{1}} \stackrel{\sim}{\sim}\right] \\
& (R) \text { or }(S)-64 \\
& \text { (ee from } 4 \text { up to } 60 \% \text { ) } \\
& \text { * means a stereogenic center }
\end{aligned}
$$

Scheme 17. Oxidative conversion of allylic selenides 90-91 into optically active.allyl alcohols 64 .

Diastereoisomeric (+) and (-)-(camphorylsulfonyl)oxaziridines 89d [50] were used for the enantioselective oxidation of 1-phenylselenyl-8-methylselenylnaphthalene 96. It was found that this reaction afforded regioselectively enantiomerically enriched 1-phenylselenyl-8methylseleninylnaphthalene $\mathbf{9 7}$, which maintains, in a standard laboratory environment, stereochemical integrity at a stereogenic seleninyl selenium atom at room temperature for several days (Scheme 18) [51]. A relatively high optical stability of the selenoxide $\mathbf{9 7}$ results from stabilization to racemization by intramolecular coordination between the dicoordinated, divalent selenium atom of the phenylselenenyl group at position 1 and a stereogenic seleninyl selenium atom at position 8 of the naphthalene ring.

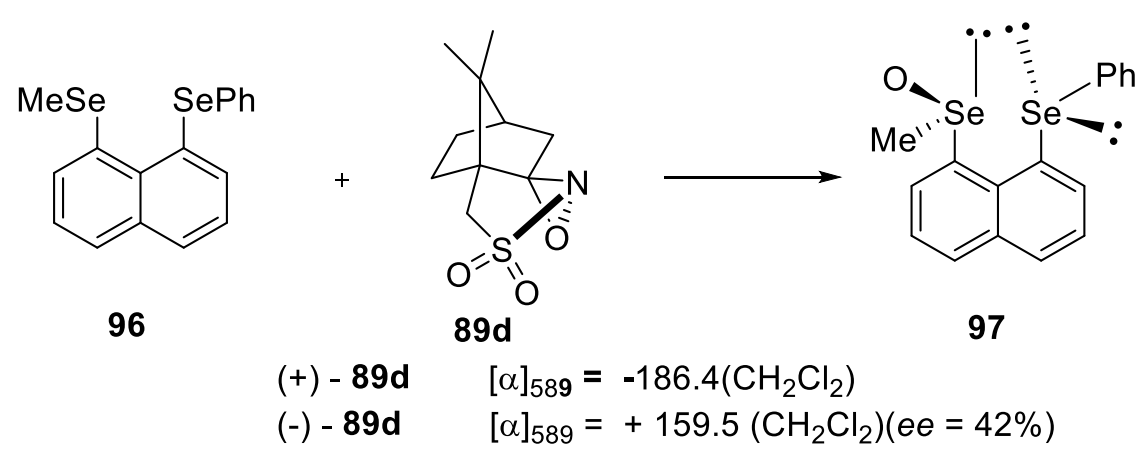

Scheme 18. Enantioselective oxidation of 1-phenylselenyl-8-methylseleninylnaphthalene 96.

A few enantiomerically enriched alkyl aryl selenoxide $\mathbf{8 6}$ and 102-105 were synthesized by the asymmetric oxidation of the corresponding alkyl aryl selenides 82 and 98-101 using a mixture of $t$-butylhydroperoxide with optically active dialkyl tartrates and titanium or aluminium tetraalkoxides such as the Lewis acids (Sharpless reagent) (Scheme 19) [52]. It was found that the most effective combination was that of diethyl tartrate (DET) and titanium tetraisopropoxide (TTIP). It gave the highest ee value (32.7\%) for methyl 2,4,6-tri-t-butylphenyl selenoxide 98 when the oxidation was carried out in methylene chloride at $-15^{\circ} \mathrm{C}$. 


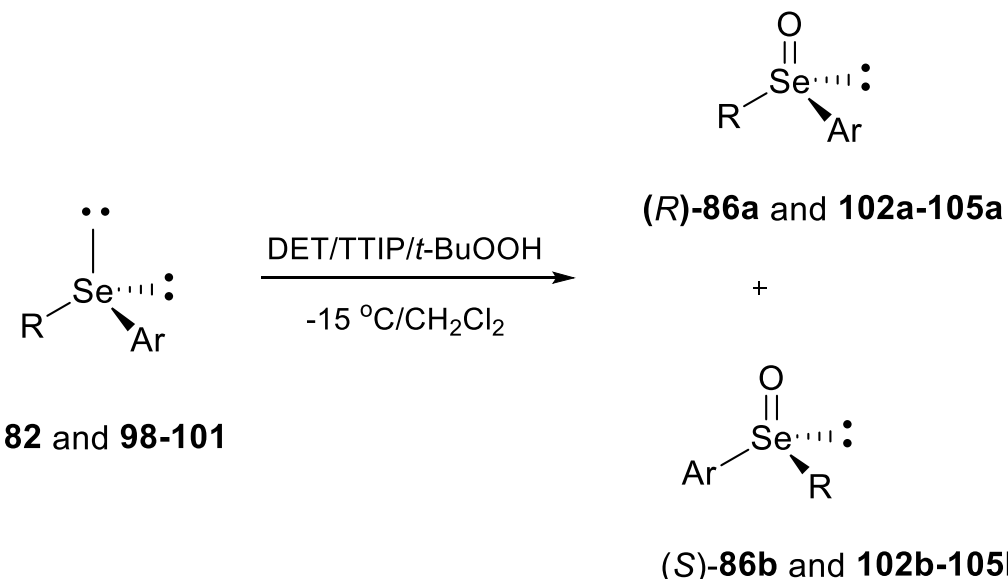
82, $\mathrm{R}=\mathrm{Me}, \mathrm{Ar}=2,4.6-i-\mathrm{Pr}_{3}-\mathrm{C}_{6} \mathrm{H}_{2}$
98, $\mathrm{R}=\mathrm{Me}, \mathrm{Ar}=2,4.6-t-\mathrm{Bu}_{3}-\mathrm{C}_{6} \mathrm{H}_{2}$
99, $\mathrm{R}=t-\mathrm{BuCH}_{2}, \mathrm{Ar}=2,4.6-t-\mathrm{Bu}_{3}-\mathrm{C}_{6} \mathrm{H}_{2}$
$100, \mathrm{R}=\mathrm{PhCH}_{2}, \mathrm{Ar}=2,4.6-t-\mathrm{Bu}_{3}-\mathrm{C}_{6} \mathrm{H}_{2}$
$101, \mathrm{R}=2-\mathrm{MeOC}_{6} \mathrm{H}_{4} \mathrm{CH}_{2}, \mathrm{Ar}=2,4.6-t-\mathrm{Bu}_{3}-\mathrm{C}_{6} \mathrm{H}_{2}$

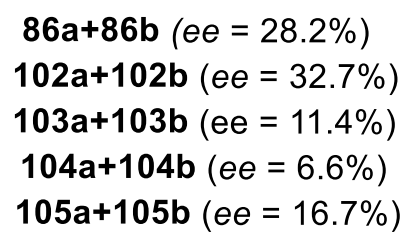

Scheme 19. Asymmetric oxidation of selenides 82 and 98-101.

Almost simultaneously, asymmetric oxidation of 2-methoxy -2,2-diphenylethyl aryl selenides 106-107 to the corresponding selenoxides 108-109 showing ee values in the range of $18-40 \%$ was reported by Tiecco at al.. They used as a reagent, $\mathrm{Ti}\left(\mathrm{OC}_{3} \mathrm{H}_{7}-\mathrm{i}\right)_{4}, \mathrm{~L}-(+)-$ or D-(-)- diisopropyltartrate (DIPT), and t-BuOOH in molar ratio 1:2:1 (Scheme 20) [53].<smiles>[R][Se]([13CH3])([13CH3])[AlH2]</smiles>

106-107<smiles>[R][Sb]([13CH3])(=O)[18O]</smiles>

$(R)-108 \mathrm{a}-109 \mathrm{a}$<smiles>[R][Se](=O)(=O)[Te]</smiles>

(S)-108b - 109b
106, $\mathrm{R}=\mathrm{Ph}_{2}(\mathrm{OMe}) \mathrm{CH}_{2}, \mathrm{Ar}=\mathrm{Ph}$
(+)-DIPT
$108 \mathrm{a}+108 \mathrm{~b}(e e=18.0 \% ;(-)-(S)$
106, $\mathrm{R}=\mathrm{Ph}_{2}(\mathrm{OMe}) \mathrm{CH}_{2}, \mathrm{Ar}=\mathrm{Ph}$
$(-)$-DIPT
$108 \mathrm{a}+108 \mathrm{~b}(\mathrm{ee}=20.0 \% ;(+)-(R)$
$109 a+109 b(e e=40.0 \% ;(-)-(S)$
107, $\mathrm{R}=\mathrm{Ph}_{2}(\mathrm{OMe}) \mathrm{CH}_{2}, \mathrm{Ar}=2-\mathrm{MeOC}_{6} \mathrm{H}_{4}(-)-\mathrm{DIPT}$

Scheme 20. Asymmetric oxidation of selenides 106-107.

In an efficient synthesis of axially chiral alkyl and aryl cyclohexylidenemethyl ketones 122-126, isolated in excellent chemical yields and with high enantiomeric excess (up to 83\% ee), based on seleninic acid elimination optically active, non-isolable cyclohexyl selenideoxides 116-121 constitute key, chiral precursors. They were prepared in situ by oxidation of cyclohexyl selenides 110-115, having 
the $\mathrm{Z}$ configuration, with either Davis camphoryloxaziridines or under Sharpless oxidation conditions (Scheme 21) [54]. The instant decomposition of non-isolable, selenoxides 133-138 (derived from some aryl vinyl selenides 127-132 using Sharpless or Davis oxidants) with elimination of an appropriate seleninic acid resulted in the formation of chiral allenyl sulfones 139-141 with up to $42 \%$ enantiomeric excess (ee) (Scheme 22)[55].

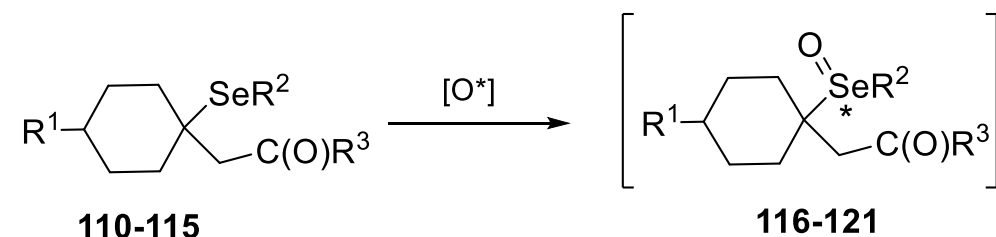

$$
\begin{array}{ll}
\mathrm{R}^{1}=\mathrm{Ph} ; \mathrm{R}^{2}=\mathrm{Me} ; \mathrm{R}^{3}=\mathrm{Ph} & 110,116 \\
\mathrm{R}^{1}=t-\mathrm{Bu} ; \mathrm{R}^{2}=\mathrm{Me} ; \mathrm{R}^{3}=\mathrm{Ph} & 111,117 \\
\mathrm{R}^{1}=t-\mathrm{Bu} ; \mathrm{R}^{2}=\mathrm{Ph} ; \mathrm{R}^{3}=\mathrm{Ph} & 112,118 \\
\mathrm{R}^{1}=\mathrm{Me} ; \mathrm{R}^{2}=\mathrm{Me} ; \mathrm{R}^{3}=\mathrm{Ph} & 113,119 \\
\mathrm{R}^{1}=t-\mathrm{Bu} ; \mathrm{R}^{2}=\mathrm{Me} ; \mathrm{R}^{3}=t-\mathrm{Bu} & 114,120 \\
\mathrm{R}^{1}=t-\mathrm{Bu} ; \mathrm{R}^{2}=\mathrm{Me} ; \mathrm{R}^{3}=\mathrm{Me} & 115,121 \\
& \\
& \\
&
\end{array}
$$

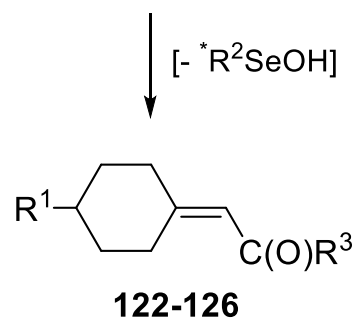

$\mathrm{R}^{1}=\mathrm{Ph} ; \mathrm{R}^{3}=\mathrm{Ph} 122$ (ee up to 83 )

$R^{1}=t-B u ; R^{3}=P h 123$ (ee up to 82)

$R^{1}=M e ; R^{3}=P h 124$ (ee up to 74 )

$R^{1}=t-B u ; R^{3}=t-B u 125$ (ee up to 74 )

$R^{1}=t-B u ; R^{3}=$ Me 126 (ee up to 81)

Scheme 21. Oxidative conversion of selenides 110-115 into optically active cyclohexylidenemethyl ketones 122-126.<smiles>[R]C=C(C[18O])[Se][14CH3]</smiles>

127-132

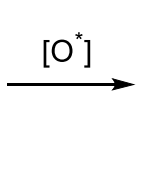

127, $133 \mathrm{R}=n-\mathrm{Pr}, \mathrm{Ar}=\mathrm{o}-\mathrm{O}_{2} \mathrm{NC}_{6} \mathrm{H}_{4}$

128, $134 \mathrm{R}=n-\mathrm{C}_{7} \mathrm{H}_{13}, \mathrm{Ar}=\mathrm{o}-\mathrm{O}_{2} \mathrm{NC}_{6} \mathrm{H}_{4}$

$129,135 \mathrm{R}=\mathrm{Cl}, \mathrm{Ar}=\mathrm{O}-\mathrm{O}_{2} \mathrm{NC}_{6} \mathrm{H}_{4}$

130, $136 \mathrm{R}=n-\mathrm{Pr}, \mathrm{Ar}=\mathrm{C}_{6} \mathrm{H}_{5}$

131, $137 \mathrm{R}=n-\mathrm{C}_{7} \mathrm{H}_{13}, \mathrm{Ar}=\mathrm{C}_{6} \mathrm{H}_{5}$

132, $138 \mathrm{R}=n-\mathrm{Pr}, \mathrm{Ar}=0-\mathrm{CF}_{3} \mathrm{C}_{6} \mathrm{H}_{4}$

* means a stereogenic center

$\mathrm{O}=$ means an oxidant (Davies oxaziridines

or Sharpless oxidation system)<smiles>[R]C=C(C[13CH3])[Se](=O)=O</smiles>

133-138<smiles>[R]/C=C\C=C/C[Y5](=O)O</smiles>

139-141

$139 \mathrm{R}=n-\mathrm{Pr}$,

$140 \mathrm{R}=n-\mathrm{C}_{7} \mathrm{H}_{13}$

$141 \mathrm{R}=\mathrm{Cl}$

Scheme 22. Oxidative conversion of aryl vinyl selenides 127-132 into optically active allenic sulfones 139-141.

$\mathrm{T}$ The treatment of phenyl tri-t-butylphenyl selenide $\mathbf{1 4 2}$ with $t$-butyl hypochlorite in the presence of (-)-2-octanol and pyridine followed by basic hydrolysis gave optically active phenyl tri-t-butylphenyl selenoxide 143 with a germinal enantiomeric excess $(e e=1 \%)($ Scheme 23) [56]. 


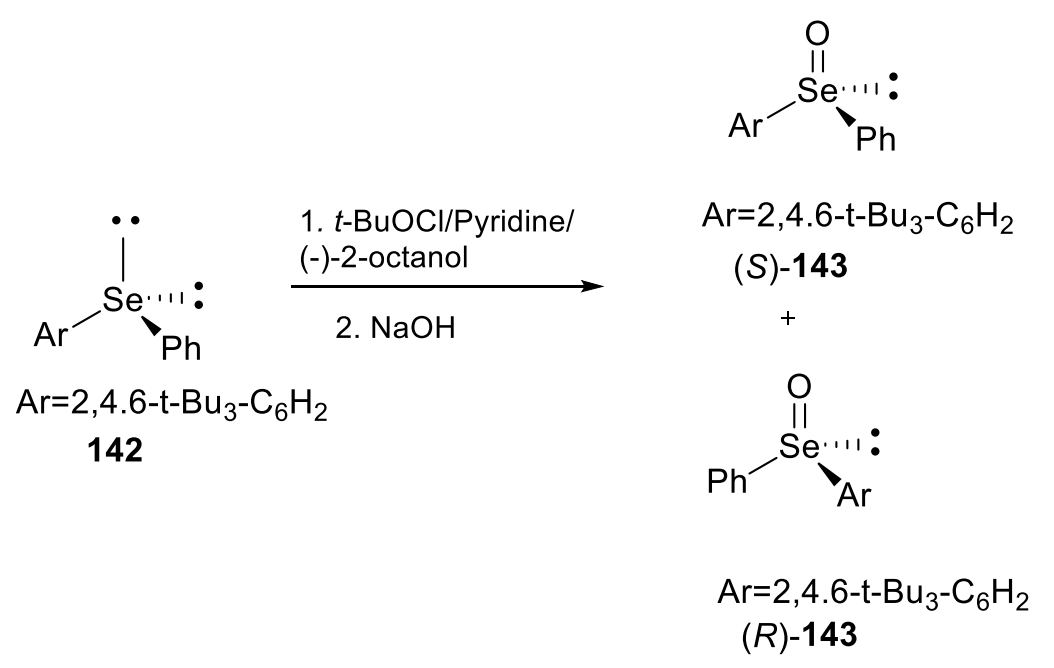

Scheme 23. Asymmetric oxidation of phenyl tri-t-butylphenyl selenide $\mathbf{1 4 2}$.

2.2.2. Chromatographic and Non-Classical Resolution of Racemates by Forming Complexes with an Optically Active Hydrogen Bond Donor

The first optical resolution by column chromatography using a chiral column was applied for diaryl selenoxides that possess no functional groups. I By this approach the racemic diaryl selenoxides 143-149 (Figure 4) were partially resolved on a medium pressure column chromatography system [(R)-iV-(3,5-dinitrobenzoyl) phenylglycine/aminopropylsilica (particle size $40 \mu$ ) columne]. Enantiomeric excess for fast eluting enantiomers ranged from 12 to $66 \%$, and for slowly eluting enantiomers from 4 to $41 \%[47,48]$.<smiles>[R16]CCC[Sb](C)(=O)c1ccccc1</smiles>

$(S)$<smiles>[R16][R9]</smiles>

$(R)$

$$
\begin{aligned}
& \mathrm{R}=t-\mathrm{Bu} ; \mathrm{Ar}=\mathrm{Ph} \quad 143 \\
& \mathrm{R}=i-\mathrm{Pr} ; \mathrm{Ar}=\mathrm{Ph} \quad 144 \\
& \mathrm{R}=i-\mathrm{Pr} ; \mathrm{Ar}=\mathrm{O}-\mathrm{MeOC}_{6} \mathrm{H}_{4} 145 \\
& \mathrm{R}=i-\mathrm{Pr} ; \mathrm{Ar}=p-\mathrm{Tol} \quad 146 \\
& \mathrm{R}=\mathrm{Et} ; \mathrm{Ar}=\mathrm{Ph} \quad 147 \\
& \mathrm{R}=\mathrm{Me} ; \mathrm{Ar}=\mathrm{Ph} \quad 148 \\
& \mathrm{R}=\mathrm{Me} ; \mathrm{Ar}=\mathrm{p}-\mathrm{Tol} \quad 149
\end{aligned}
$$

Figure 4. diaryl selenoxides 143-149 that possess no functional groups.

Later on, column chromatography on a chiral column was applied to separate enantiomers selenoxides configurationally stabilized by intramolecular coordination to the stereogenic selenium atom. Thus, racemic 2-((dimethylamino)methyl)phenyl alkyl (or aryl) selenoxides 150-152 (Figure 5), containing an amino group able to coordinate with the selenium atom, were resolved into enantiomers by means of HPLC chromatography using an chiral column It is interesting to note that the. vthe stabilization energy (ca. $3 \mathrm{kcal} \mathrm{mol}^{-1}$ ) for this interaction was determined by variable temperature ${ }^{1} \mathrm{H}-\mathrm{NNMR}$ experiments [59]. 
<smiles>[R][Se](=O)(=O)c1ccccc1CN(C)C</smiles>

$(+)-(R)$

$$
\begin{aligned}
& \mathrm{R}=\mathrm{Me} 150 \\
& \mathrm{R}=\mathrm{PhCH}_{2} 151 \\
& \mathrm{R}=\mathrm{Ph} 152
\end{aligned}
$$<smiles>[R][Se](=O)(=O)c1ccccc1CNC</smiles>

$(-)-(S)$

Figure 5. 2-(Dimethylamino)methyl)phenyl alkyl (aryl) selenoxides 150-152.

A similar optical resolution (Figure 6) was applied to racemic 2-(methylchalcogenomethyl)diphenyl selenoxides 153-154 and 2-\{2_-(N, N-dimethylamino)ethyl $\}$-phenyl alkyl (or aryl) selenoxides 156-158. However, selenoxide 155 could not be resolved by this procedure [60].<smiles>CCCc1ccccc1[Se](=O)(=O)c1ccccc1</smiles>

$(+)-(R)$

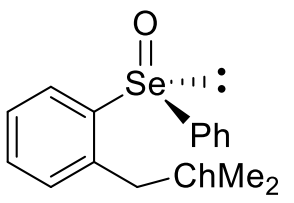

$(-)-(S)$<smiles>[R][Sb](C)(=O)c1ccccc1CCN(C)C</smiles>

$(+)-(R)$<smiles>[R][Sb]([1H])(=O)c1ccccc1CCN(C)C</smiles>

$(-)-(S)$

$$
\begin{aligned}
& \text { Ch }=\text { O } 153(\text { ee }=100 \%(S) \text { and } 60 \%(R) \\
& \text { Ch }=\text { S } 154(\text { ee }=75 \%(S) \text { and } 60 \%(R) \\
& \text { Ch }=\text { Se } 155(\text { ee }=0 \%(S) \text { and } 0 \%(R)
\end{aligned}
$$$$
\mathrm{R}=\mathrm{Ph} 156(\text { ee }=100 \%(S) \text { and } 60 \%(R)
$$$$
\mathrm{R}=\mathrm{PhCH}_{2} 157(\mathrm{ee}=100 \%(S) \text { and } 75 \%(R)
$$

Figure 6. 2-2-(Methylchalcogenomethyl)diphenyl selenoxides 153-154 and 2-\{2_-(N,N-dimethylamino) ethyl\}-phenyl alkyl (or aryl) selenoxides 156-158.

Three enantiomerically pure 8-(dimethylamino)-1-aryl(alkyl)-naphthyl selenoxides 159-161 (Figure 7) were isolated by chromatographic resolution using a chiral column ((Daicel Chiralpak AS; $10 \times 250 \mathrm{~mm}$ ). It is interesting to note that the first eluted enantiomer of selenoxide 159 had a positive specific rotation, whereas the first eluted enantiomer of selenoxides 160-161 had a negative specific rotation $[61,62]$.<smiles>[R][Se](=O)c1cccc2cccc(N(C)C)c12</smiles>

$\mathrm{R}=$ Me 159 (ee $=100 \%$ for $(+)$ (fast) and $100 \%$ for $(-)$ (slow)

$\mathrm{R}=\mathrm{Ph} 160$ (ee $=100 \%$ for $(-)$ (fast) and $80 \%$ for $(+)$ (slow)

$\mathrm{R}=2,4,6-(i-\mathrm{Pr})_{3} \mathrm{C}_{6} \mathrm{H}_{2} 161$ (ee = 100\% for (-)(fast) and $90 \%$ for (-)(slow)

Figure 7. 8-(Dimethylamino)-1-aryl(alkyl)-naphthyl selenoxides 159-161.

In addition to chromatographic resolutions mentioned above, several simple aryl alkyl 85 and 162-167 and dialkyl selenoxides 168-170 (Figure 8) were resolved into pure enantiomers via complexation with enantiomerically pure 2,2'-dihydroxy-1,1'-binaphthol 171 or 1,6-di(o-chlorophenyl)-1,6-diphenylhexa-2,4-diyne-1,6-diol 172. Enantiomeric excess of sulfoxides selenoxides 85 and 162-167 in the complex with 171 was found to be almost 100\%. Moreover, dynamic kinetic resolution (DKR) of selenoxides via hydrate formation gave in some cases enantiomerically pure selenoxides in yields above 100\% [63]. 


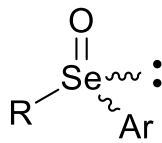

$\mathrm{R}=\mathrm{Me} ; \mathrm{Ar}=\mathrm{Ph} \quad 85$

$\mathrm{R}=\mathrm{Et} ; \mathrm{Ar}=\mathrm{Ph} 162$

$\mathrm{R}=\mathrm{Me} ; \mathrm{Ar}=0-\mathrm{MeC}_{6} \mathrm{H}_{4} 163$

$\mathrm{R}=\mathrm{Et} ; \mathrm{Ar}=\mathrm{o}-\mathrm{MeC}_{6} \mathrm{H}_{4} 164$

$\mathrm{R}=\mathrm{Me} ; \mathrm{Ar}=m-\mathrm{MeC}_{6} \mathrm{H}_{4} 165$

$\mathrm{R}=\mathrm{Et} ; \mathrm{Ar}=m-\mathrm{MeC}_{6} \mathrm{H}_{4} 166$

$\mathrm{R}=\mathrm{Et} ; \mathrm{Ar}=p-\mathrm{MeC}_{6} \mathrm{H}_{4} 167$<smiles>[R][R]([R])([14CH3])[14CH3]</smiles>

$\mathrm{R}^{1}=n-\mathrm{Bu} ; \mathrm{R}^{2}=\mathrm{Et} \quad \mathbf{1 6 8}$

$\mathrm{R}^{1}=\mathrm{C}_{7} \mathrm{H}_{15} ; \mathrm{R}^{2}=$ Me 169

$\mathrm{R}^{1}=\mathrm{C}_{7} \mathrm{H}_{15} ; \mathrm{R}^{2}=$ Et $\mathbf{1 7 0}$<smiles>Oc1ccc2ccccc2c1-c1c(O)ccc2ccccc12</smiles>

171

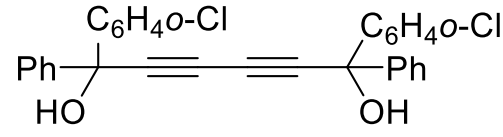

172

Figure 8. Aryl alkyl 85 and 162-167 and dialkyl selenoxides 168-170.

\subsubsection{Kinetic Resolution of Racemates}

In fact, the first optically active, enantiomerically enriched selenoxides were isolated in a kinetic resolution reaction when racemic methyl phenyl selenoxide 85 or methyl tri-isopropylphenyl selenoxide $\mathbf{8 6}$ were subjected to the reaction with a half molar equivalent of (-)- or (+)-camphorsulfonamide $\mathbf{1 7 3}$ (Scheme 24) [64].<smiles>[R][Sb]([13CH3])(=O)=O</smiles><smiles>[R]N</smiles>
173

85, 174; $\mathrm{R}=\mathrm{Me}, \mathrm{Ar}=\mathrm{Ph}$

86, 175; $\mathrm{R}=\mathrm{Me}, \mathrm{Ar}=(i-\mathrm{Pr})_{3} \mathrm{C}_{6} \mathrm{H}_{2}$

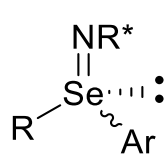

174-175<smiles>[R][Sb]([14CH3])(=O)=O</smiles>

$(-)$ or $(+)-85$

$(-)$ or $(+)-86$

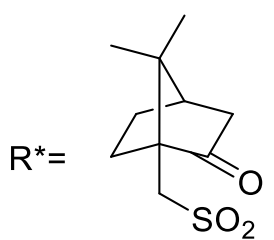

Scheme 24. Kinetic resolution reaction of racemic alkyl phenyl selenoxides 85-86.

\subsubsection{Reaction of Enantiopure, Cyclic Seleninic Ester with an Organometallic Reagent}

There is a single literature report on a conversion of optically active, cyclic seleninate ester into optically active selenoxide. Thus, the reaction of optically active seleninate ester $(+)-(R)-\mathbf{1 7 6}$ with ee equal to $98 \%$, (obtained by HPLC chromatography on a chiral column) and methylmagnesium bromide was found to afford with retention of configuration at the stereogenic selenium atom, 2-(hydroxymethyl)-4,6-di-t-butylphenyl methyl selenoxide $(-)-(R)-177(e e=97 \%)(S c h e m e ~ 25)$ [65]. 


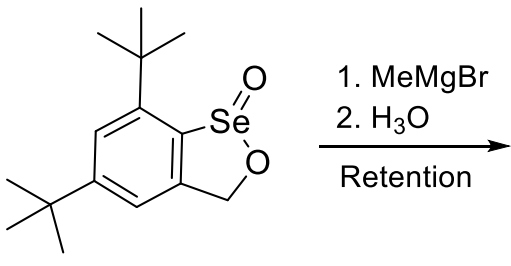

$(-)-R-176$

ee $=98 \%$

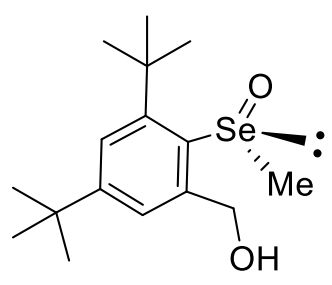

$(+)-R-177$ ee $=97 \%$

Scheme 25. Reaction of optically active seleninate ester (+)-(R)-176 with methylmagnesium bromide.

\section{Absolute Configurations and Enantiomeric Excesses of Optically Active Selenoxides}

The absolute configuration of the levorotatory enantiomer of selenoxide $\mathbf{7 8}$ was established to be $S$, taking into accounts the result of X-ray crystallographic analysis of the diastereoisomerically pure, levorotatory selenoxide 76a and the lack of inversion of configuration around the stereogenic selenium atom during the transesterification from (-)-( $\left.S_{\text {se }}\right)-76$ to methyl esters (-)-78 (Scheme 14) [45]. This determination was also supported by the presence of negative Cotton effects at the same wavelength region $(284 \mathrm{~nm})$ in the circular dichroism CD spectra of (-)-(76) and (-)-(78). The (S) absolute configurations around the stereogenic selenium atom of the other selenoxides (-)-(77) and (-)-(79) were deduced from their CD spectra in which also negative Cotton effects in this region $(292 \mathrm{~nm})$ were observed. The enantiomeric excesses of the selenoxides mentioned above were determined by HPLC using a chiral column. The extent of the asymmetric induction during the asymmetric oxidation of methyl phenyl selenide $\mathbf{8 1}$ to the corresponding selenoxide 85 (Scheme 16) was determined by adding to their solution successive amounts of tris[3-(heptafluoropropylhydroxymethylene d-camphorate]-europlum (III), Eu(hfc) 3 . The absolute configuration around the stereogenic selenium atom of the selenoxide 85 was determined by the analysis of ${ }^{1} \mathrm{H}-\mathrm{NMR}$ spectra recorded for the reaction mixture or for the isolated sample in the presence of (+)-2,2,2-trifluoro-1-(9-anthryl)ethanol. The extent of the asymmetric induction during the enantiselective oxidation of 1-phenylselenyl-8-methylselenylnaphthalene 96 to the corresponding, enantiomerically enriched 1-phenylselenyl-8-methylseleninylnaphthalene 97 (Scheme 18) was determined by analyzing ${ }^{1} \mathrm{H}-\mathrm{NMR}$ spectra of the isolated selenoxide 97 measured in the presence of enantiomerically pure BINOL or t-butylphenylphosphinothioic acid as a chiral solvating agent (CSA). The extent of the asymmetric induction during the asymmetric oxidation of alkyl aryl selenides 82 and 98-101 to the corresponding selenoxides $\mathbf{8 6}$ and 102-105 with Sharpless reagent (Scheme 19) [52] was determined by ${ }^{1} \mathrm{H}$-NMR using tris[3-(heptafluoropropylhydroxymethylene d-camphorate]-europlum (III), Eu(hfc) $)_{3}$ as chiral shift reagent (CSR). Their absolute configurations were suggested based upon comparison with circular dichroism spectra of the appropriate alkyl aryl sulfoxides. The $S$ absolute configuration of the levorotatory enantiomers of 2-(dimethylamino)methyl)phenyl alkyl (or aryl) selenoxides 150-152 was suggested by comparison of their specific rotations, circular dichroism spectra, and behavior on the optically active column with those of the sulfur analogue [44]. The common features that exist between the CD spectra of selenoxides 143-149 and optically active p-tolyl mesityl sulfoxide and p-tolyl 2,4,6-triisopropylphenyl sulfoxide were used to assign the absolute configuration of the dextrarotatory selenoxide enantiomers $[57,58]$. The relationship between the absolute configurations around a stereogenic selenium atom of 2-(methylchalcogenomethyl)diphenyl selenoxides 153-154 and 2-\{2-(N,N-dimethylamino)ethyl\}-phenyl alkyl (or aryl) selenoxides 156-158 and the chiroptical properties of the enantiomers of was clarified by comparing with those of sulfur analogues [60]. Earlier, the absolute configurations of the optically active chalcogen oxides 159-161 were assigned by comparison of their specific rotations and CD spectra with those of their sulfur analog $[61,62]$. Similarly, the absolute configuration of dextrorotatory 2-(hydroxymethyl) phenyl methyl selenoxide (+)-177 was determined to be $\mathrm{R}$ by comparison of its specific rotations and CD spectra with those of that (R)-2-(hydroxymethyl) phenyl methyl sulfoxide. Enantiomeric excess of selenoxides 85 and 162-167 in 
their complexes with BINOL 171 was determined from the ${ }^{1} \mathrm{H}-\mathrm{NMR}$ spectra [48]. The optical excesses of 2-methoxy-2, 2-diphenylethyl aryl selenoxides 108-109 were determined by HPLC using a chiral column [53].

\section{Configurational Stability of Optically Active Selenoxides}

Bearing in mind the very close structural similarity between sulfoxides and selenoxides it can be expected, simply by analogy, that the same racemization mechanisms will operate for different selenoxides. Three basic mechanism of thermally induced racemization of sulfoxides, including a pyramidal inversion, are very well understood, mainly due to the classical studies of the Mislow's group [66-68]. At the same time, extensive studies, mainly from the Oae group, explained in detail various chemically induced racemization of the reach family of sulfoxides [68,69]. In contrast to sulfoxides, mechanistic studies on thermally and chemically induced racemization of selenoxides are rather limited. There is only a single paper devoted to thermal racemization of selenoxides by a pyramidal inversion mechanism. In this publication, the free energies of activation $\left(A G^{*}\right)$ for the epimerization of a few diastereoisomeric, optically active diaryl selenoxides have been reported. They were calculated on the basis of the coalescence temperature of signals of two nonequivalent ${ }^{77} \mathrm{Se}$ nuclei observed in the ${ }^{77}$ Se- NMR spectra of a series of diasteroisomeric 4-[(-)-menthyloxycarbonyl] phenyl 2,4,6-tri-alkylphenyl selenoxides 76, $\mathbf{7 7}$ and 178-180 (Figure 9). These values, ranging from 61 to $85.8 \mathrm{~kJ} \mathrm{~mol}^{-1}$, clearly indicate that the rate of epimerization of the selenoxides is strongly dependent on the bulkiness of the ortho substituents [70]. It should be noted here that the activation barriers for alkyl aryl and diaryl sulfoxides are considerably higher (150-180 kJ/ mol) [66-68].

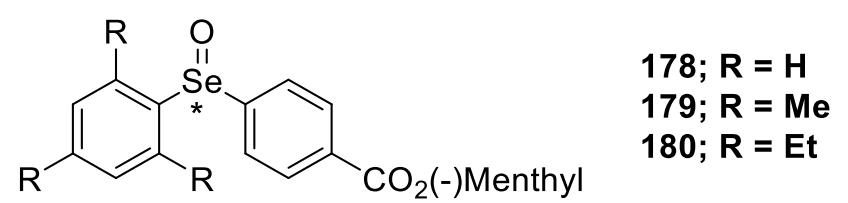

Figure 9. 4-[(-)-Menthyloxycarbonyl] phenyl 2,4,6-tri-alkylphenyl selenoxides 178-180.

The facile formation of achiral hydrates, mentioned for the first time in the paper which reported the first unsuccessful attempts to resolve 4-carboxydiphenyl selenoxide 8 and 4-carboxyphenyl methyl selenoxide 9 via diastereoisomeric salts with brucine, L-menthylamine, and enantiomerically pure $\alpha$-phenylethylamine [18], can be considered as an oldest example of the chemically induced racemization of selenoxides. Later, racemization of selenoxides 143-144, 147-148 and 150-152 was studied in detail by CD measurements $[57,58]$ In a chloroform solution, the CD spectra of selenoxides 150-152 were unchanged even after five days. However, racemization was observed in methanol and addition of water to the methanol solution accelerated this racemization. These results indicate that the racemization in methanol was caused by a trace amount of water. The half-lives of racemization for selenoxide (S)-(-)-152 corresponded well with those for selenoxide $(R)-(+)-\mathbf{1 4 8}$. Moreover, racemization of $(S)-(-)-\mathbf{1 5 0 - 1 5 2}$, was accelerated by the addition of $p$-toluenesulfonic acid or sodium hydroxide, especially in the case of (S)-(-)-150, whereas the racemization of selenoxide $(R)-(+)-\mathbf{1 4 8}$ was not accelerated by the addition of sodium hydroxide. This results can be explained if one assumes operation of the mechanism shown for selenoxide 1a on Scheme 26. According to this mechanism the formation of hydroxyselenonium salt $\mathbf{1 8 1}$ is the rate determining step (RDS) in acidic media, whereas racemization in basic media is caused by the addition of hydroxide ion to a selenium atom in 1a followed by protonation of the oxygen atom in $\mathbf{1 8 2}$ to give an achiral hydrate $\mathbf{1 0 .}$ 
<smiles>[R]CC[Se]([R])(=O)[O-]</smiles>

(S\}-1a

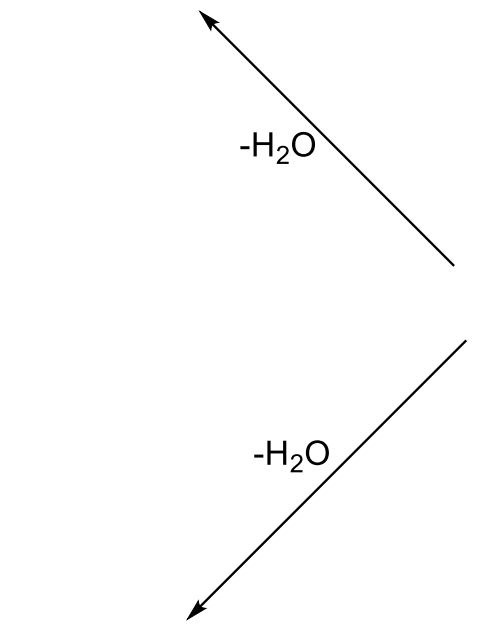<smiles>[R]CC[Se]([R])(C)O</smiles>

(S\}-181<smiles></smiles>

(R)-1a

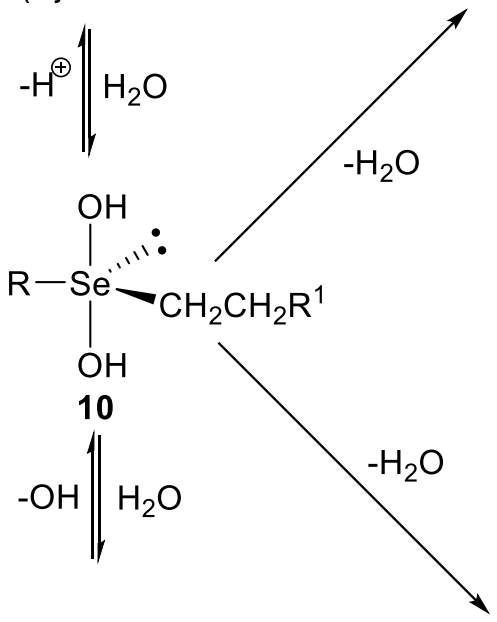<smiles>[R]CC[Ge]([R])([14CH3])O</smiles>

182<smiles></smiles>

$(R\}-1 \mathbf{a}$

(S\}-1a

descriptors (S) and (R) are valid

if in selenoxide $1 \mathrm{a}$ or hydroxysulfonium salt $181 \mathrm{R}$ has priority over $\mathrm{CH}_{2} \mathrm{CH}_{2} \mathrm{R}^{1}$ (according to the Cahn-Ingold-Prelog rules)

Scheme 26. The mechanism of racemization of selenoxides by the formation of hydrates in the presence of water.

The half-lives of racemization for selenoxides 162-166 complexed with BINOL 171, determined by polarymetric measurements at $19{ }^{\circ} \mathrm{C}$, was found to be in the range of minutes (from 6.5 to 19.5) in methanol, while for the complex of the selenoxide 164 dissolved in chloroform was equal to $3.7 \mathrm{~h}$ [63].

\section{Conclusions}

In the present review, synthetic approaches to the preparation of non-racemic selenoxides and the problem of their optical stability are described. The purpose of this mini review is to provide available information on both topics in order to stimulate additional research in this field. The rationale for this research topic is the structural similarity between selenoxides and sulfoxides, which play a very important role as new synthetic reagents, biologically active compounds and new functional materials [71]. Therefore, it is reasonable to expect that optically active selenoxides should be just as useful as sulfoxides when they have sufficiently high optical stability. The literature data discussed in this review show how this goal can be achieved, and this is the main reason for publishing it in its current form. It is reasonable to expect that further research will allow the preparation of model compounds containing sterically demanding substituents, which in turn enable the preparation of optically active selenoxides with optical stability comparable to sulfoxides. Experimental works currently carried in our laboratories, focused on methodological and stereochemical aspects of flow processes [72] and mechanochemical procedures, allow us to have legitimate hope for reaching this goal. 
Author Contributions: The contribution of all authors in the preparation of the manuscript is equivalent. All authors have read and agreed to the published version of the manuscript.

Funding: The writing of this manuscript was financially supported by the National Science Center, grant number UMO-2014/15/B/ ST5/05329 (for JD).

Acknowledgments: We would thank Prof. P. Kiełbasiński for helpful comments during the preparation of this manuscript. We are also very grateful to the anonymous referees for their comments.

Conflicts of Interest: The authors declare no conflict of interest. The funders had no role in the writing of the manuscript.

\section{References}

1. Twidell, T.T. Oxidation of Alcohols by Activated Dimethyl Sulofoxide and Related Reactions. Synthesis 1990, 10, 857-870. [CrossRef]

2. Młochowski, J.; Lisiak, R.; Wójtowicz-Młochowska, H. Organoselenium and Organotellurium Oxidation and Reduction. In PATAI'S Chemistry of Functional Groups; Wiley: Hoboken, NJ, USA, 2011; pp. 1083-1160.

3. Ponthieux, S.; Paulmier, C. Selenium-Stabilized Carboanions. Organselenium Chem. 2000, 208, 113-142.

4. Mikolajczyk, M.; Drabowicz, J.; Kielbasinski, P. Chiral Sulfur Reagents: Applications in Asymmetric and Stereoselective Synthesis; CRC Press: Boca Raton, FL, USA, 1998.

5. Nishibayashi, Y. Uemura Selenoxide Elimination and [2,3]Sigmatropic Rearrangement. Organselenium Chem. 2000, 208, 201-234.

6. Nomoto, A.; Ogawa, A. ChemInform Abstract: Preparative Uses of Organoselenium and Organotellurium Compounds. In The Chemistry of Organic Selenium and Tellurium Compounds; Rappoport, Z., Ed.; John Wiley and Sons: Hoboken, NJ, USA, 2012; pp. 623-688.

7. Ishii, A.; Matsubayashi, T.; Takahashi, T.; Nakayama, J. Preparation of a selenenic acid and isolation of selenoseleninates. J. Org. Chem. 1999, 64, 1084-1085. [CrossRef]

8. Reich, H.J.; Jasperse, C.P. Organoselenium chemistry. Preparation and reactions of 2,4,6-tri-tert-butylbenzeneselenenic acid. J. Org. Chem. 1988, 53, 2389-2390. [CrossRef]

9. Goto, K.; Nagahama, M.; Mizushima, T.; Shimada, K.; Kawashima, T.; Okazaki, R. The first direct oxidative conversion of a selenol to a stable selenenic acid: Experimental demonstration of three processes included in the catalytic cycle of glutathione peroxidase. Org. Lett. 2001, 3, 3569-3572. [CrossRef]

10. Penn, R.E.; Block, E.; Revelle, L.K. Methanesulfenic Acid. J. Am. Chem. Soc. 1978, 100, 3622-3624. [CrossRef]

11. Goto, K.; Holler, M.; Okazaki, R. Synthesis, Structure, and Reactions of a Sulfenic Acid Bearing a Novel Bowl-Type Substituent: The First Synthesis of a Stable Sulfenic Acid by Direct Oxidation of a Thiol. J. Am. Chem. Soc. 1997, 119, 1460-1461. [CrossRef]

12. Ishii, A.; Komiya, K.; Nakayama, J. Synthesis of a Stable Sulfenic Acid by Oxidation of a Sterically Hindered Thiol (Thiophenetriptycene-8-thiol)1 and Its Characterization. J. Am.Chem. Soc. 1996, 118, 12836-12837. [CrossRef]

13. Rheinboldt, H.; Giesbrecht, E. The Configuration of Organic Selenoxides: Mixed Crystals of Selenoxides with Sulfoxides. J. Am. Chem. Soc. 1946, 68, 2671-2673. [CrossRef]

14. Rheinboldt, H.; Giesbrecht, E. Mixed Crystals of Sulfoxides, Sulfones, Selenoxides and Selenones. J. Am. Chem. Soc. 1947, 69, 644-646. [CrossRef]

15. Gaythwaite, W.R.; Kenyon, J.; Phillips, H. CCXCVII.-The quadrivalency of selenium. Part I. 4-Carboxydiphenyl and p-carboxyphenyl methyl selenoxides. J. Chem. Soc. 1928, 2280-2287. [CrossRef]

16. Harrison, A.; Kenyon, J.; Phillips, J. Phillips. J. Chem. Soc. 1926, 2079-2786. [CrossRef]

17. Campbell, T.W.; Walker, H.G.; Coppinger, G.M. Some Aspects of the Organic Chemistry of Selenium. Chem. Rev. 1952, 50, 279-349. [CrossRef]

18. Ōki, M.; Iwamura, H. The configuration of the selenoxides. Tetrahedron Lett. 1966, 7, 2917-2920. [CrossRef]

19. Burlant, W.J.; Gould, E.S. Metalation of Dibenzoselenophene. J. Am. Chem. Soc. 1954, 76, 5775-5776. [CrossRef]

20. Cinquini, M.; Colonna, S.; Landini, D. Diastereomeric diselenoxides. Bol. Sci. Fac. Chim. Ind. Bol. 1969, 27, 207-209.

21. Musher, J.I. The Chemistry of Hypervalent Molecules. Angew. Chem. Int. Ed. 1969, 8, 54-68. [CrossRef]

22. Akiba, K. Chemistry of Hypervalent Compounds; Akiba, K., Ed.; Wiley-VCH: New York, NY, USA, 1999. 
23. Drabowicz, J.; Halaba, G. ChemInform Abstract: Stereochemical Aspect of the Chemistry of Hypervalent Chalcogen Compounds. Cheminform 2010, 33, 1-32. [CrossRef]

24. Drabowicz, J.; Kiełbasiński, P.; Zając, A.; Pokora-Sobczak, P. Hypervalent Selenium Derivatives. In Organoselenium Chemistry between Synthesis and Biochemistry; Santi, C., Ed.; Bentham Science Publishers: Sharjah, United Arab Emirates, 2014; pp. 120-145.

25. Komatsu, N.; Uemura, S. Recent Advances in Asymmetric Synthesis Using Organochalcogen Compounds. J. Synth. Org. Chem. 1995, 53, 268-274. [CrossRef]

26. Kamigata, N.; Shimizu, T. Synthesis and Stereochemistry of Optically Active Selenoxides. J. Synth. Org. Chem. 1990, 48, 229-239. [CrossRef]

27. Kobayashi, M.; Shimizu, T. Synthesis of the Optically Active Diaryl Selenoxides. Cheminform 1987, 7, 1437-1441.

28. Kamigata, N. Synthesis and Stereochemistry of Chiral Selenoxides and Telluroxides. Phosphorus Sulfur Silicon Relat. Elem. 2001, 171, 207-229. [CrossRef]

29. Uemura, S. Application of Asymmetric Oxidation and Imidation of Organic Selenides to Organic Transformations. Phosphorus Sulfur Silicon Relat. Elem. 2001, 171, 13-30. [CrossRef]

30. Drabowicz, J.; Kiełbasiński, P.; Zajac, A. Hypervalent Derivatives of Selenium and Tellurium. In PATAI'S Chemistry of Functional Groups; Wiley: Hoboken, NJ, USA, 2011; pp. 891-948.

31. Jones, D.N.; Mundy, D.; Whitehouse, R.D. Steroidal selenoxides diastereoisomeric at selenium; syn-elimination, absolute configuration, and optical rotatory dispersion characteristics. J. Chem. Soc. D 1970, 2, 86-87. [CrossRef]

32. Ayrey, G.; Barnard, D.; Woodbridge, D.T. 401. The oxidation of organoselenium compounds by ozone. J. Chem. Soc. 1962, 2089-2099. [CrossRef]

33. Cram, D.J. Steric Effects in Organic Chemistry; Newman, M., Ed.; Wiley: New York, NY, USA, 1956.

34. Salmond, W.; Barta, M.; Cain, A.; Sobala, M. Alternative modes of decomposition of allylic selenoxides diastereoisomeric at selenium. Preparation of $\Delta 5,7$ - and $5 \beta$-hydroxy- $\Delta 6$-steroiods. Tetrahedron Lett. 1977, 18 , 1683-1686. [CrossRef]

35. Back, T.G.; Ibrahim, N.; McPhee, D.J. Studies of enamidic. DELTA.5-4-azasteroidal selenoxides: Preparation, Pummerer reactions, configurational stability, and conversion to carbinol amides. J. Org. Chem. 1982, 47, 3283-3289. [CrossRef]

36. Kurose, N.; Takahashi, T.; Koizumi, T. First synthesis of optically pure selenuranes and stereoselective alkaline hydrolysis. Their application to asymmetric [2,3]sigmatropic rearrangement of allylic selenoxides. Tetrahedron 1997, 53, 12115-12129. [CrossRef]

37. Takahashi, T.; Kurose, N.; Kawanami, S.; Arai, Y.; Koizumi, T.; Shiro, M. Optically Pure Haloselenuranes. First Synthesis and Nucleophilic Substitutions. J. Org. Chem. 1994, 59, 3262-3264. [CrossRef]

38. Paulmier, C. Selenium Reagents and Intermediates in Organic Synthesis; Baldwin, J.E., Ed.; Pergamon Press: Oxford, UK, 1986.

39. Kamigata, N.; Shimizu, T. Reviews on Heteroatom Chemistry; Oae, S., Ed.; MYU: Tokyo, Japan, 1991.

40. Tomoda, S.; Usuki, Y.; Fujita, K.; Iwaoka, M. Reviews on Heteroatom Chemistry; Oae, S., Ed.; MYU: Tokyo, Japan, 1991.

41. Reich, H.J. Organoselenium Chemistry; Liotta, D., Ed.; John Wiley \& Sons: New York, NY, USA, 1987.

42. Reich, H.J.; Yelm, K.E. Asymmetric induction in the oxidation of [2.2]paracyclophane-substituted selenides. Application of chirality transfer in the selenoxide [2,3]sigmatropic rearrangement. J. Org. Chem. 1991, 56, 5672-5679. [CrossRef]

43. Kawakami, R.; Singh, J.D.; Fukuzawa, S.-I.; Uemura, S. Synthesis of [R,S;R,S]- and [S,R;S,R]-Bis[2 -[1-(dimethylamino)ethyl]ferrocenyl] Diselenides and Their Application to Asymmetric Selenoxide Elimination and [2,3]Sigmatropic Rearrangement. J. Org. Chem. 1995, 60, 4114-4120.

44. Fujita, K.-I.; Kanakubo, M.; Ushijima, H.; Oishi, A.; Ikeda, Y.; Taguchi, Y. Asymmetric [2,3]Sigmatropic Rearrangement of Optically Active Allylic Selenides. Synlett 1998, 1998, 987-988. [CrossRef]

45. Shimizu, T.; Kikuchi, K.; Ishikawa, Y.; Ikemoto, I.; Kobayashi, M.; Kamigata, N. Synthesis and absolute configuration of optically active selenoxides. X-Ray molecular structure of (-) se -4-menthyloxycarbonylphenyl 2,4,6-tri-isopropylphenyl selenoxide. J. Chem. Soc. Perkin Trans. 1989, 1, 597-602. [CrossRef] 
46. Shimizu, T.; Seki, N.; Taka, H.; Kamigata, N. Stereoselective Transformation of Optically Active Selenoxide into Optically Active Selenonium Imide. J. Org. Chem. 1996, 61, 6013-6014. [CrossRef]

47. Davis, F.A.; Stringer, O.D.; McCauley, J.P. Asymmetric oxidation of achiral selenides to optically active selenoxides. Tetrahedron 1985, 41, 4747-4757. [CrossRef]

48. Davis, F.A.; ThimmaReddy, R.; Weismiller, M.C. (-)-.alpha.,.alpha.-Dichlorocamphorsulfonyloxaziridine: A superior reagent for the asymmetric oxidation of sulfides to sulfoxides. J. Am. Chem. Soc. 1989, 111, 5964-5965. [CrossRef]

49. Davis, F.A.; Reddy, R.T. Asymmetric oxidation of simple selenides to selenoxides in high enantiopurity. Stereochemical aspects of the allyl selenoxide/allyl selenenate rearrangement. J. Org. Chem. 1992, 57, 2599-2606. [CrossRef]

50. Davis, F.A.; Towson, J.C.; Weismiller, M.C.; Lal, S.; Carroll, P.J. Chemistry of oxaziridines. 11. (Camphorylsulfonyl)oxaziridine: Synthesis and properties. J. Am. Chem. Soc. 1988, 110, 8477-8482. [CrossRef]

51. Drabowicz, J.; Nakanishi, W.; Haiashi, S. Unpublished preliminary results, manuscript in preparation. 2020.

52. Shimizu, T.; Kobayashi, M.; Kamigata, N. Asymmetric oxidation of alkyl aryl selenides under Sharpless oxidation conditions. Bull. Chem. Soc. Jpn. 1989, 62, 2099-2101. [CrossRef]

53. Tiecco, M.; Tingoli, M.; Testaferri, L.; Bartoli, D. Asymmetric oxidation of prochiral selenides to optically active selenoxides. Tetrahedron Lett. 1987, 28, 3849-3852. [CrossRef]

54. Komatsu, N.; Matsunaga, S.; Sugita, T.; Uemura, S. Asymmetric selenoxide elimination leading to chiral alkyl and aryl cyclohexylidenemethyl ketones. J. Am. Chem. Soc. 1993, 115, 5847-5848. [CrossRef]

55. Komatsu, N.; Murakami, T.; Kawakami, R.; Sugita, T.; Uemura, S. Asymmetric selenoxide elimination leading to chiral allenic sulfones. J. Org. Chem. 1993, 58, 3697-3702. [CrossRef]

56. Kobayashi, M.; Ohkubo, H.; Shimizu, T. Synthesis of selenoxides by oxidation of selenides with t-butyl hypochlorite, and its application for synthesis of optically active selenoxide. Bull. Chem. Soc. Jpn. 1986, 59, 503-506. [CrossRef]

57. Shimizu, T.; Kobayashi, M. Optically active selenoxides: Chromatographic separation and absolute configuration. J. Org. Chem. 1987, 52, 3399-3403. [CrossRef]

58. Shimizu, T.; Kobayashi, M. Optical resolution of asymmetric selenoxides by high-performance liquid chromatography using optically active column. Bull. Chem. Soc. Jpn. 1986, 59, 2654-2656. [CrossRef]

59. Shimizu, T.; Enomoto, M.; Taka, H.; Kamigata, N. Optical Resolution and Configurational Stability of Selenoxides Stabilized by Intramolecular Coordination. J. Org. Chem. 1999, 64, 8242-8247. [CrossRef]

60. Soma, T.; Shimizu, T.; Hirabayashi, K.; Kamigata, N. Stabilizing effect of intramolecular lewis base toward racemization of optically active selenoxides. Heteroat. Chem. 2007, 18, 301-311. [CrossRef]

61. Taka, H.; Matsumoto, A.; Shimizu, T.; Kamigata, N. Thermodynamically stabilized chiral chalcogen oxides: Optical resolution and stereochemistry. Heteroat. Chem. 2001, 12, 227-237. [CrossRef]

62. Taka, H.; Matsumoto, A.; Shimizu, T.; Kamigata, N. Optical Resolution of Thermodynamically Stabilized Selenoxides by 8-(Dimethylamino)-1-naphthyl Group. Chem. Lett. 2000, 29, 726-727. [CrossRef]

63. Toda, F.; Mori, K. Optical resolution of selenoxides by complexation with optically active 2,2?-dihydroxy-1,1?-binaphthol or 1,6-di(o-chlorophenyl)-1,6-diphenylhexa-2,4-diyne-1,6-diol. J. Chem. Soc., Chem. Commun. 1986, 1357-1359. [CrossRef]

64. Davis, F.A.; Billmers, J.M.; Stringer, O.D. First synthesis of simple optically active selenoxides. Tetrahedron Lett. 1983, 24, 3191-3194. [CrossRef]

65. Nakashima, Y.; Shimizu, T.; Hirabayashi, K.; Iwasaki, F.; Yamasaki, M.; Kamigata, N. Optically Active Seleninate Esters: Isolation, Absolute Configuration, Racemization Mechanism, and Transformation into Chiral Selenoxide. J. Org. Chem. 2005, 70, 5020-5027. [CrossRef] [PubMed]

66. Rayner, D.R.; Gordon, A.J.; Mislow, K. Thermal racemization of diaryl, alkyl aryl, and dialkyl sulfoxides by pyramidal inversion. J. Am. Chem. Soc. 1968, 90, 4854-4860. [CrossRef]

67. Andersen, K.K. Sulphones and Sulphoxides (1988); Patai, S., Rappoport, Z., Stirling, C., Eds.; John Wiley \& Sons: Chichester, UK, 1988.

68. Mikołajczyk, M.; Drabowicz, J.; Mikoajczyk, M. Chiral Organosulfur Compounds. In Topics in Stereochemistry; Wiley: Hoboken, NJ, USA, 2007; Volume 13, pp. 333-468.

69. Oae, S.; Yokoyama, M.; Kise, M. Oxygen Exchange and Racemization Reactions of Sulfoxides in Acetic and Chloroacetic Acid. Bull. Chem. Soc. Jpn. 1968, 41, 1221-1224. [CrossRef] 
70. Shimizu, T.; Yoshida, M.; Kobayashi, M. An estimation of the configurational stability of diaryl selenoxides by means of 77Se NMR spectroscopy. Bull. Chem. Soc. Jpn. 1987, 60, 1555-1557. [CrossRef]

71. Han, J.; Soloshonok, V.A.; Klika, K.D.; Drabowicz, J.; Wzorek, A. SDE-Phoric functional groups. Chiral Sulfoxides: Asymmetric preparation and problems with the accurate determination of the stereochemical outcome. Chem. Soc. Rev. 2018, 47, 1307-1350. [CrossRef]

72. Jasiak, A.; Mielniczak, G.; Owsianik, K.; Koprowski, M.; Krasowska, D.; Drabowicz, J. Solvent-Free Michaelis-Arbuzov Rearrangement under Flow Conditions. J. Org. Chem. 2019, 84, 2619-2625. [CrossRef]

(C) 2020 by the authors. Licensee MDPI, Basel, Switzerland. This article is an open access article distributed under the terms and conditions of the Creative Commons Attribution (CC BY) license (http://creativecommons.org/licenses/by/4.0/). 